Article

\title{
The Benefits of the Ka-Band as Evidenced from the SARAL/AltiKa Altimetric Mission: Quality Assessment and Unique Characteristics of AltiKa Data
}

\author{
Pascal Bonnefond ${ }^{1, *}$, Jacques Verron ${ }^{2}$, Jérémie Aublanc ${ }^{3}$, K. N. Babu ${ }^{4}$, Muriel Bergé-Nguyen ${ }^{5}$, \\ Mathilde Cancet ${ }^{6}$, Aditya Chaudhary ${ }^{4}$, Jean-François Crétaux ${ }^{5}$, Frédéric Frappart ${ }^{5,7}$, \\ Bruce J. Haines ${ }^{8}$, Olivier Laurain ${ }^{9}$, Annabelle Ollivier ${ }^{3}$, Jean-Christophe Poisson ${ }^{3}$, \\ Pierre Prandi ${ }^{3}$, Rashmi Sharma ${ }^{4}$, Pierre Thibaut ${ }^{3}$ and Christopher Watson ${ }^{10}$ \\ 1 SYRTE, Observatoire de Paris, PSL Research University, CNRS, Sorbonne Universités, UPMC Univ. Paris 06, \\ LNE, 75014 Paris, France \\ 2 Institut des Géosciences de l'Environnement (IGE)/CNRS, 38041 Grenoble, France; \\ Jacques.Verron@univ-grenoble-alpes.fr \\ 3 Collecte Localisation Satellites (CLS), 31520 Ramonville Saint-Agne, France; jaublanc@cls.fr (J.A.); \\ aollivier@cls.fr (A.O.); jpoisson@cls.fr (J.-C.P.); pprandi@cls.fr (P.P.); pthibaut@cls.fr (P.T.) \\ 4 Space Applications Centre (ISRO), Ahmedabad 380015, India; kn_babu@sac.isro.gov.in (K.N.B.); \\ aditya.osd@sac.isro.gov.in (A.C.); rashmi@sac.isro.gov.in (R.S.) \\ 5 Laboratoire d'Etudes en Géophysique et Océanographie Spatiales (LEGOS), 31400 Toulouse, France; \\ Muriel.Berge-Nguyen@cnes.fr (M.B.-N.); Jean-Francois.Cretaux@legos.obs-mip.fr (J.-F.C.); \\ Frederic.Frappart@legos.obs-mip.fr (F.F.) \\ 6 NOVELTIS, 31670 Labège, France; Mathilde.Cancet@noveltis.fr \\ 7 Géosciences Environnement Toulouse (GET), 31400 Toulouse, France \\ 8 Jet Propulsion Laboratory, California Institute of Technology, Pasadena, CA 91109, USA; \\ Bruce.J.Haines@jpl.nasa.gov \\ 9 Géoazur-Observatoire de la Côte d'Azur, 06905 Sophia-Antipolis, France; Olivier.Laurain@oca.eu \\ 10 Surveying and Spatial Science Group, School of Geography and Environmental Studies, \\ University of Tasmania, Hobart 7001, Australia; Christopher.Watson@utas.edu.au \\ * Correspondence: Pascal.Bonnefond@obspm.fr; Tel.: +33-1-40-51-22-29
}

Received: 6 December 2017; Accepted: 6 January 2018; Published: 9 January 2018

\begin{abstract}
The India-France SARAL/AltiKa mission is the first Ka-band altimetric mission dedicated to oceanography. The mission objectives are primarily the observation of the oceanic mesoscales but also include coastal oceanography, global and regional sea level monitoring, data assimilation, and operational oceanography. The mission ended its nominal phase after 3 years in orbit and began a new phase (drifting orbit) in July 2016. The objective of this paper is to provide a state of the art of the achievements of the SARAL/AltiKa mission in terms of quality assessment and unique characteristics of AltiKa data. It shows that the AltiKa data have similar accuracy at the centimeter level in term of absolute water level whatever the method (from local to global) and the type of water surfaces (ocean and lakes). It shows also that beyond the fact that AltiKa data quality meets the expectations and initial mission requirements, the unique characteristics of the altimeter and the Ka-band offer unique contributions in fields that were previously not fully foreseen.
\end{abstract}

Keywords: altimetry; Ka-band; data processing; calibration; validation 


\section{Introduction}

Launched in February 2013, the SARAL/AltiKa mission carries the first Ka-band altimeter ever flown [1]. The primary mission objective is the observation of the oceanic mesoscales, as well as coastal oceanography, global and regional sea level monitoring, data assimilation and operational oceanography. Secondary objectives include ice sheet, sea ice and inland waters monitoring. In order to continue the time series and to benefit from the existing mean sea surface, SARAL flew on the same orbit as Envisat. The SARAL/AltiKa mission was considered as a "gap filler" between Envisat (lost in April 2012) and Sentinel-3A (launched in February 2016) and has permitted to continue the sea level measurements on the historical ground track of the ERS-1\&2 and Envisat missions. The nominal phase of the mission was planned to end three years after launch with an objective of five years. Since July 2016, SARAL/AltiKa has left its nominal orbit and entered in a Drifting Phase until its end of life. This phase, seamless in term of accuracy, provides a larger data coverage (Figure 1). The new orbit (altitude increased by $1 \mathrm{~km}$ ) allows to improve the mean sea surface resolution but has been chosen to maintain also a good temporal resolution (15-20 days) for mesoscale studies.

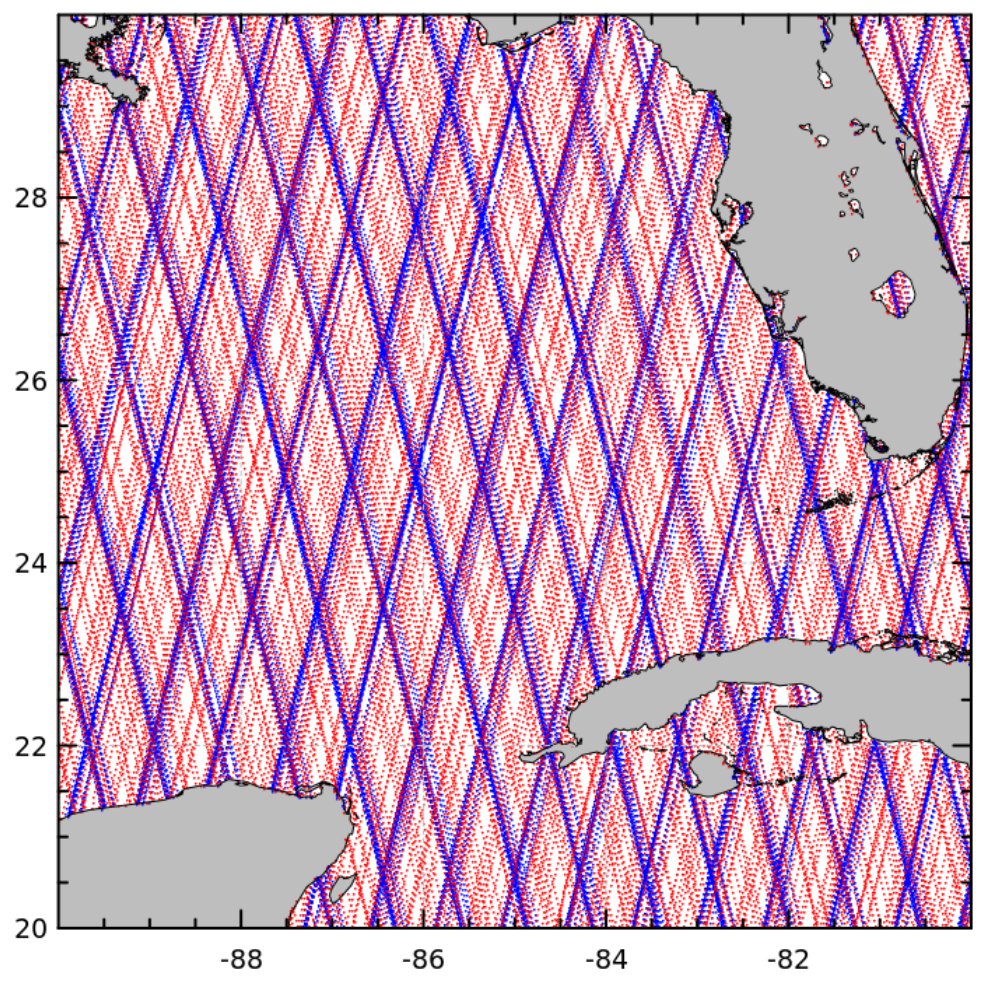

Figure 1. Blue: Repetitive orbit ground track. Red: Drifting orbit ground track.

SARAL/AltiKa's main scientific objective is to provide data products to the oceanographic research user community for studies to improve our knowledge of the ocean mesoscale variability, thanks to the improvement in spatial and vertical resolution brought by SARAL/AltiKa. This main scientific objective is divided into subthemes of mesoscale ocean dynamics: observations, theoretical analyses, modelling, data assimilation, and so forth. This leads to an improvement of our understanding of the climate system through its key ocean component and especially the role and impact of mesoscale features on the climate variability at large spatial and temporal scales. It also contributes to the study of coastal dynamics, which is important for many downstream applications including operational oceanography, which seeks large amounts of in-situ and space-based data.

SARAL/AltiKa's secondary objectives include the monitoring of the main continental water levels (i.e., lakes, rivers, and enclosed seas), the monitoring of large-scale sea level variations, the observation of polar oceans (thanks to the high inclination of its orbit), the analysis and forecast of wave and wind 
fields, the study of continental ice (thanks to the lower penetration in Ka-band) and sea ice, the access to low rains climatology (enabled in counterpart to the sensitivity of Ka-band to clouds and low rains) and the marine biogeochemistry (notably through the role of the meso- and submeso-scale physics).

The success of SARAL/AltiKa has been made possible by a very fruitful cooperation and efficient joint work between ISRO and CNES and thanks to the highly valuable exchanges between scientists of both countries. The objective of this paper is to highlights salient results in terms of quality assessment and unique characteristics of AltiKa data made since the special issue published in 2015 (Marine Geodesy, 38(S1):1, 2015, [2]). This paper is preceded by a companion paper focusing on the scientific applications where more details about the SARAL/AltiKa mission and its payload are also given [3]. In the first section of this paper, we will focus on the quality assessment of water level through Calibration and Validation and the second section will illustrate some unique contributions of Ka-band information in AltiKa data.

\section{Quality Assessment of Water Level through Calibration and Validation}

The observation of rising mean sea levels over the Earth's oceans using satellite altimetry has helped inform and shape the debate on global climate change that has emerged over the last two decades [4]. The ongoing monitoring of secular changes in global mean sea level with accuracy tolerances of better than $1 \mathrm{~mm}$ /year remains a fundamental science goal within satellite altimetry and represents one of the most challenging objectives in space geodesy. Central to this objective has been the recognition that calibration and validation (cal/val) are vital components of the altimeter measurement system technique. Cal/val defines a multi-disciplinary problem in and of itself, that pushes the limits of available terrestrial, oceanographic and space based observational techniques. Current estimates of regional and global change in mean sea level are only possible with careful and ongoing calibration of altimeter missions. Cross calibration of past, current and future altimeter missions will remain essential for continued sea-level studies.

During the last years, complementary altimetric missions operating concurrently have provided the unprecedented ability to compare measurement systems by undertaking relative calibrations. Studies have demonstrated through global statistics the power of such a technique [5,6]. Given the technical challenges of operating spacecraft for many years in orbit, however, the ability to cross-calibrate multiple missions in this manner cannot be assured. It reinforces the need for a range of complementary calibration methodologies-including a geographically diverse array of in situ absolute calibration sites that can assess changes to instrument behavior in near real time: such facilities, as described in [7], provide in situ sea level measurements in the same reference frame than the satellite altimetry ones and correct them from solid earth vertical motions.

The cal/val activities are focused not only on the important continuity between past, present and future missions but also on the reliability between offshore, coastal and inland altimetric measurement. The ability to sample varied geographically correlated errors and characterize them in an absolute sense are significant benefits of a well-distributed set of calibration sites. There is no doubt, however, that the "calibration task" requires a multifaceted approach, including both in situ calibration sites and regional/global studies.

This section will provide metrics of the SARAL/AltiKa accuracy and precision through absolute calibration sites (Section 2.1), global approach (Section 2.3) and an in between regional approach (Section 2.2). The main achievement of the data quality assessment provided in this section is illustrated in Figure 2 showing that AltiKa data have similar accuracy at the centimeter level in terms of absolute water level whatever the method (from local to global) and the type of water surfaces (ocean and lakes). This illustrates the improvement in altimetry in the last decade thanks to better processing and geophysical corrections but more importantly thanks to new technology (Ka-band, SAR) that paved the way of new frontiers in altimetry. Remaining differences from the various determinations shown in Figure 2 illustrate the characteristics of the studied water level (open-ocean, coastal, inland) but also the remaining errors coming from the methods used and the geodetic datum of each sites. 
Another important result is that cal/val activities over lakes are now at the same level of accuracy than the ones performed over decades at historical calibration sites (Bass Strait, Corsica, Crete, and Harvest).
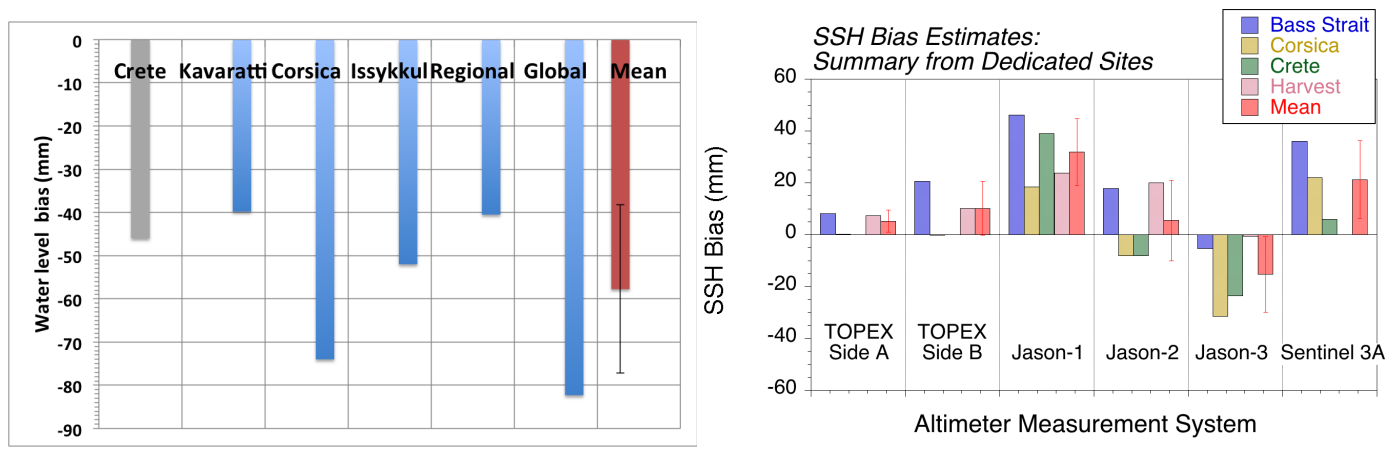

Figure 2. Left (this study): water level bias from Crete [8], Kavaratti (Section 2.1.1), Corsica (Section 2.1.2, Lake Issykul (Section 2.1.3), the regional (Section 2.2) and global (Section 2.3) approaches. The mean value of all the determinations is $-54 \mathrm{~mm}$ with a standard deviation of $15 \mathrm{~mm}$. Right [9]: TOPEX, Jason and Sentinel-3A Sea Surface Height (SSH) biases from in situ calibration sites.

\subsection{Water Level Calibration from Open-Ocean, Coastal and Inland Waters In Situ Absolute Calibration Sites}

\subsubsection{Kavaratti, Altimeters' Calibration Site}

The Kavaratti site gives an opportunity to do absolute calibration of altimeters over the tropical region. This calibration site do not show altimeter land contamination since it is in the open ocean, which gives it an added advantage. Kavaratti Island, is located southwest of Indian peninsula, $\sim 450 \mathrm{~km}$ from the coast, as a platform of scientific observations, it has historic measurements from many Indian scientific institutions (e.g., Survey of India specific to water level). Figure 3 represents the part of Arabian Sea with Lakshadweep Islands at north and Maldives Islands at south. This permanent facility in Kavaratti is situated near the ground tracks of TOPEX/Jason and SARAL/AltiKa missions. The dedicated calibration facility at Kavaratti includes tide gauges, meteorological and oceanographic instruments, and a bottom pressure recorder [10]. This site has long-term sea level measurement at the tide gauge station TG1, which allows for the precise estimation of drift in sea surface height. The site characterization and calibration experiment and its results can be found in [10].

The absolute calibration of SARAL/AtiKa is carried out for its 23 cycles at this site (Figure 4). The determined absolute bias is $-39.8 \mathrm{~mm}$ with standard deviation of $23.6 \mathrm{~mm}$. In this AltiKa calibration exercise we have not used any local high resolution tide models, also the effects of wind and atmospheric pressures, and vertical land motion for the precise local geoid estimation are disregarded in determining the absolute Sea Surface Height (SSH) bias. These results and the good agreement with other in situ calibration sites shows that the location is robust and encourages us to continue observations to carry out the absolute calibration of altimetric SSH. The errors in estimation of absolute SARAL/AltiKa bias over this site will be improved through future field experiments. 


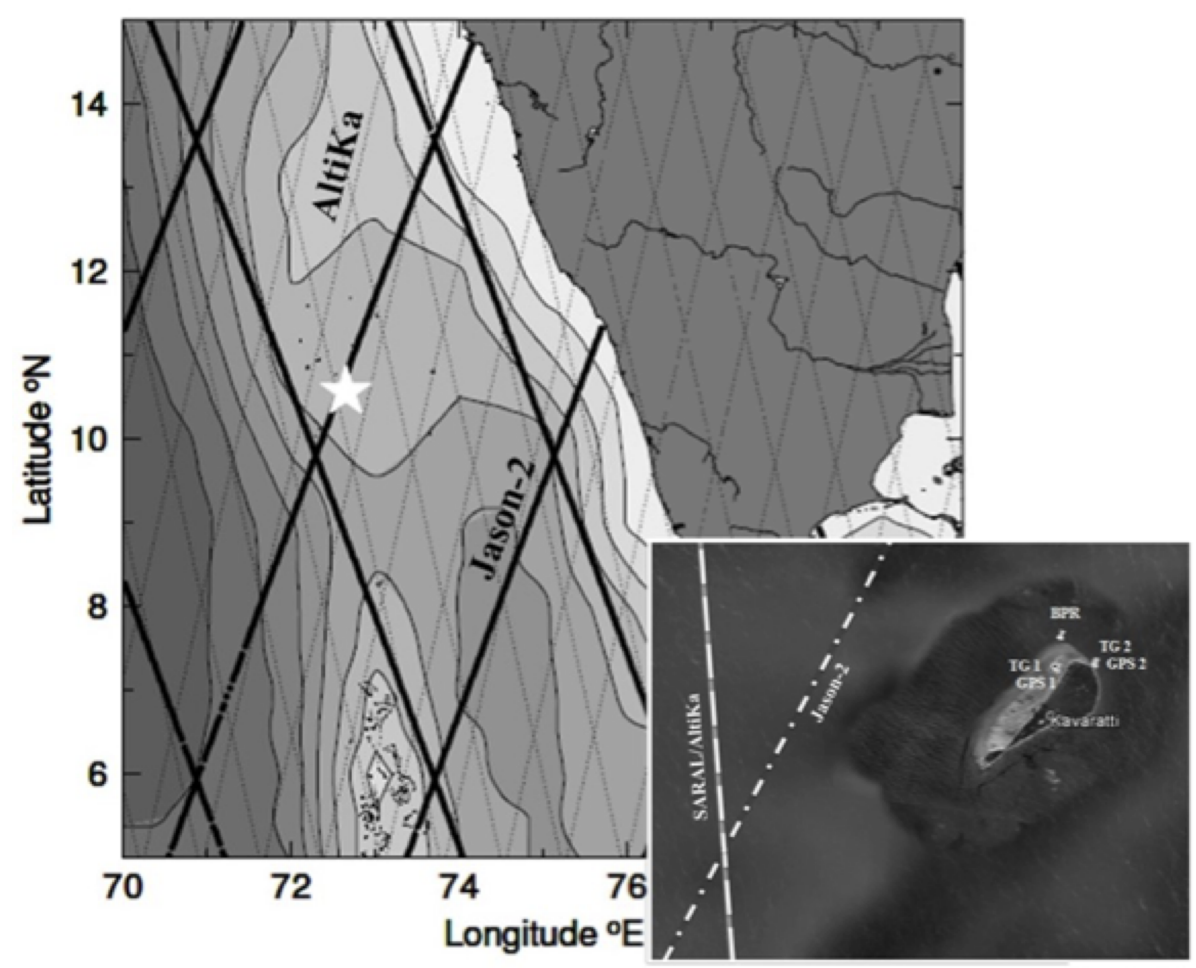

Figure 3. The large map shows the location of Kavaratti island (star) as well as the Jason-2 and SARAL/AltiKa ground tracks. The insert is a zoom of Kavaratti: ISRO's altimeter calibration site, has dual radar tide gauge station and a bottom pressure recorder.

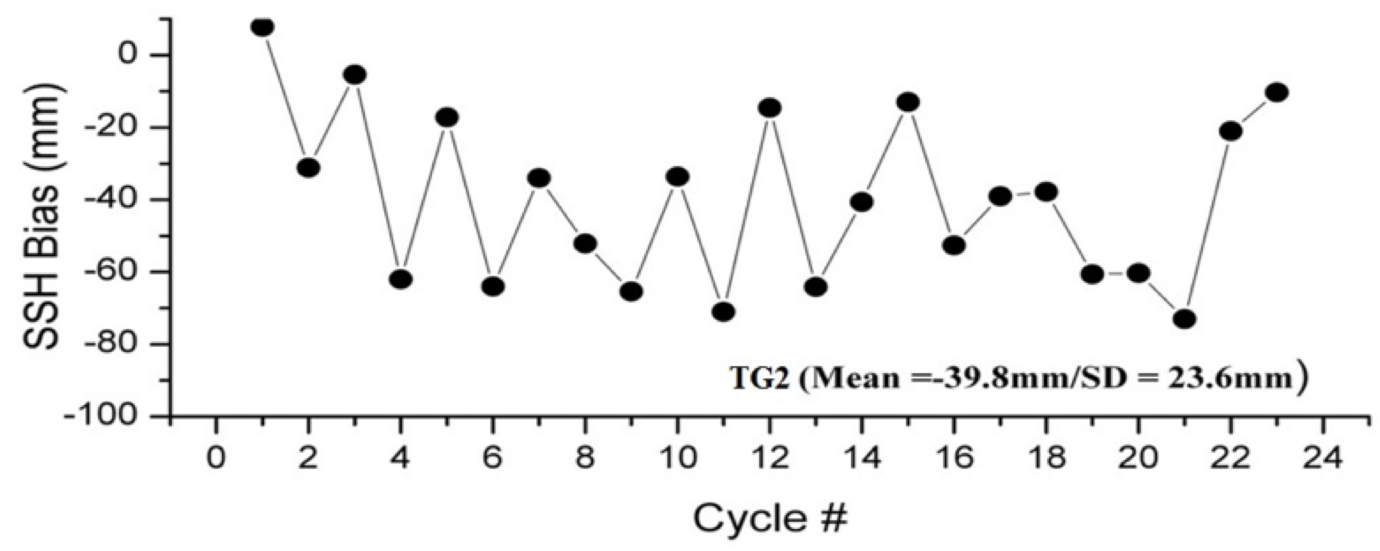

Figure 4. Absolute sea surface height bias of SARAL/AltiKa from cycle 1 to 23 using GDR-T products.

\subsubsection{SARAL/AltiKa Absolute Calibration over Corsica during the Nominal and Drifting Phases}

The geodetic Corsica site was set up in 1998 in order to perform altimeter calibration of the TOPEX/Poseidon (T/P) mission and subsequently, Jason-1, OSTM/Jason-2 and Jason-3. The scope of the site was widened in 2005 in order to undertake the calibration of the Envisat mission and most recently of SARAL/AltiKa. In [11], we have presented the first results from the latter mission using both indirect and direct calibration/validation approaches. The indirect approach utilizes a coastal tide gauge and, as a consequence, the altimeter derived Sea Surface Height (SSH) needs to be corrected for the geoid slope. The direct approach utilizes a novel GPS-based system deployed offshore under the satellite ground track that permits a direct comparison with the altimeter derived $\mathrm{SSH}$. This latter approach has the advantage being able to be used without any specific infrastructure and have permitted us to make measurements even during the period when the difficulties with the 
satellite reaction wheels did not permit the ground track to be accurately maintained (from March 2015 until the Drifting Phase in July 2016): this is illustrated in the bottom part of Figure 5 and the SSH biases derived from those configurations (bold red circles) are in agreement with the whole time series. Since the beginning of the Drifting Phase, SARAL/AltiKa have overflown the Corsica calibration sites (Ajaccio and Senetosa) in different configurations illustrated in the right part of Figure 5. The SSH biases have then been computed using Senetosa or Ajaccio tide gauges or even both (cycle 100/pass 735 and cycle 104/pass 677) when the satellite have overflown both geoid areas (shaded in purple on Figure 5 maps). The results for these configurations (bold blue crosses in Figure 5) are also in very good agreement with the whole time series, even in a configuration very close to the coast $(\sim 3-4 \mathrm{~km}$, cycle 100/pass 735). The overflights of both Senetosa and Ajaccio sites have permitted us to compare the SSH bias from Ajaccio and Senetosa tide gauges and we found an offset of $30 \mathrm{~mm}$ which is due to an issue in the absolute reference of Ajaccio tide gauge. This problem was identified in [11] and has been solved recently. This is discussed in [12] in which we have performed the Sentinel-3A calibration over both Senetosa and Ajaccio sites in a configuration close to the one encountered with SARAL/AltiKa for cycle 104 and pass 677 (see Figure 5).

In conclusion, in this analysis, after correcting the $30 \mathrm{~mm}$ offset in the Ajaccio tide gauge measurements, we demonstrate that using either indirect or direct calibration/validation approach gives similar SSH bias, respectively $-74 \pm 4 \mathrm{~mm}$ and $-69 \pm 11 \mathrm{~mm}$. Even during the Drifting Phase, we can continue to monitor the SSH bias using both approaches with a good agreement compared to the whole time series and a period close to the initial ones (46 days in average compared to the 35-day repeat period in the nominal phase).

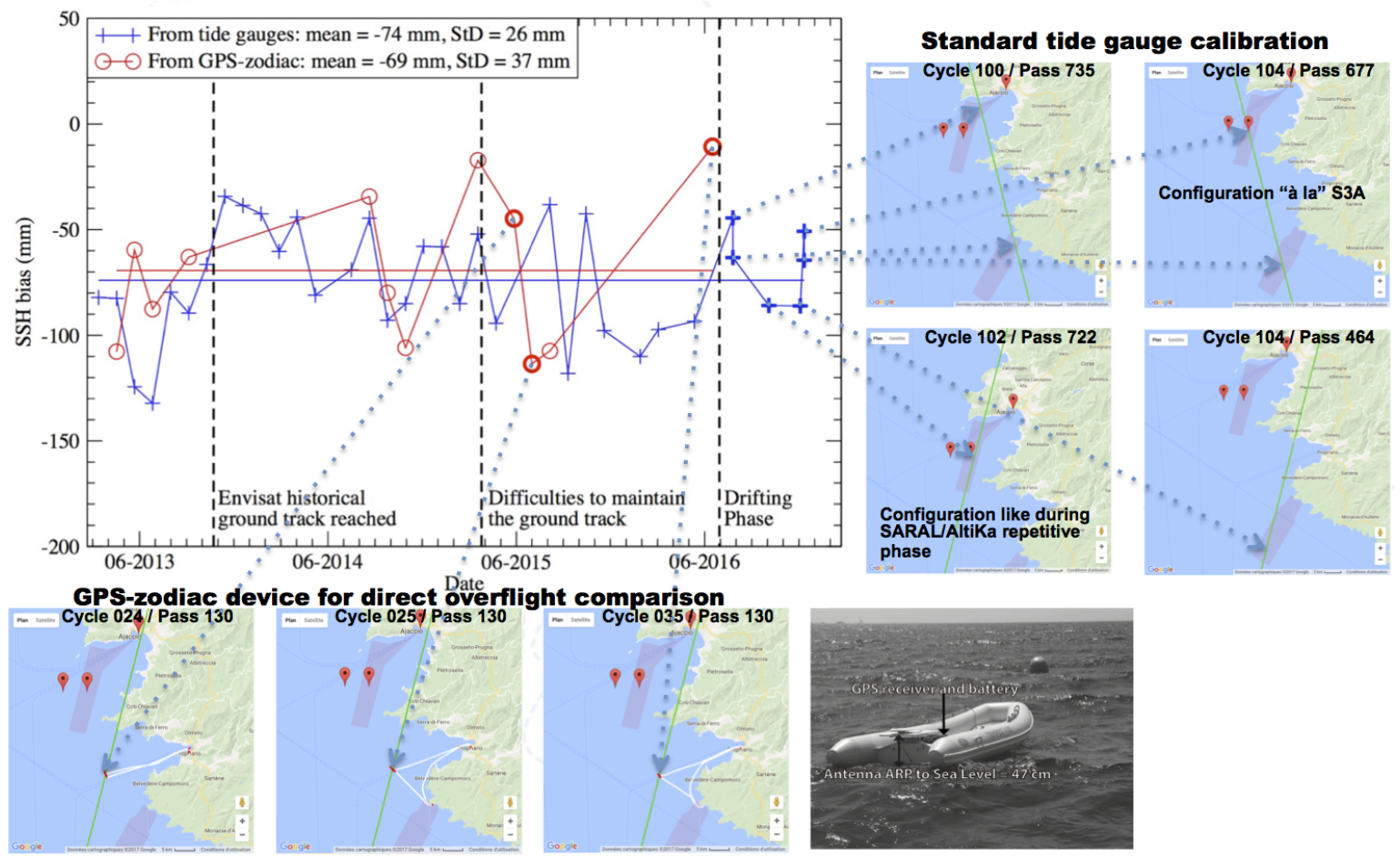

Figure 5. Sea Surface Height (SSH) bias time series for SARAL/AltiKa over Corsica for both direct (GPS-zodiac, red circles) and indirect (tide gauges, blue crosses) approaches. The bold symbols correspond to situations where the satellite was not overflying the calibration sites in a nominal configuration.

\subsubsection{Absolute Calibration, Validation of SARAL/AltiKa over the Lake Issykkul}

SARAL/AltiKa is used over the continents to measure the water height changes of lakes and rivers [1]. In order to determine the performances of altimeters over inland waters, a dedicated site 
of calibration/validation has been setup in 2004 over the lake Issykkul. Lake Issykkul $\left(42-43^{\circ} \mathrm{N}\right.$, $\left.76-79^{\circ} \mathrm{E}\right)$ is a large lake $\left(6000 \mathrm{~km}^{2}\right.$ of area extent) located in Kyrgyzstan in Central Asia. Initially used as experimental site, thanks to promising first results obtained with TOPEX/Poseidon [13], the Lake Issykkul became permanent cal/val site for several altimeters in orbit. It has served for Jason-1, Jason-2, and Envisat with results coherent with other cal/val sites over the oceans [14,15]. The interest of having cal/val sites over a lake is to benefit from specific conditions of inland water (no tides, no inverse barometer) and to quantify the accuracy of altimeters to measure their water level changes.

Meanwhile, some corrections like the wet or dry tropospheric delay are not measured as accurately as over the ocean. Using ground instrumentation over the lake Issykkul therefore helps quantifying the error budget of altimeters over lakes in general. Since 2004, not less than 15 field campaigns have been done over the Lake Issykkul. The full experimental design is given in [16] and is not described here in details. In few words, it simply consists in measuring the water level changes along the track of the satellite, due to the geoid's gradient (which over the Lake Issykkul reaches several meters over long distance) using a GPS kinematic survey on a boat following the satellite tracks. It allows us to calculate the absolute bias of the altimeter.

First of all, the water level changes of the Lake Issykkul from 2013 to 2016 are calculated every 35 days using the altimetry data from the SARAL/AltiKa instrument. It is compared to the water level changes measured at an historical floating tide gauge located on the north coast of the lake (providing daily water level). It is also compared to hourly water level changes of the Lake measured by a radar installed on the south east lake shoreline. These comparisons allow us to quantify the accuracy of SARAL/AltiKa over the lake Issykkul in particular, which gives an order of magnitude of accuracy of this instrument for large lakes in general. It confirms results obtained in [17] that SARAL/ AltiKa allows us to measure water level changes at very high accuracy $(3.5 \mathrm{~cm}$ for lake Issykkul: Figure 6).

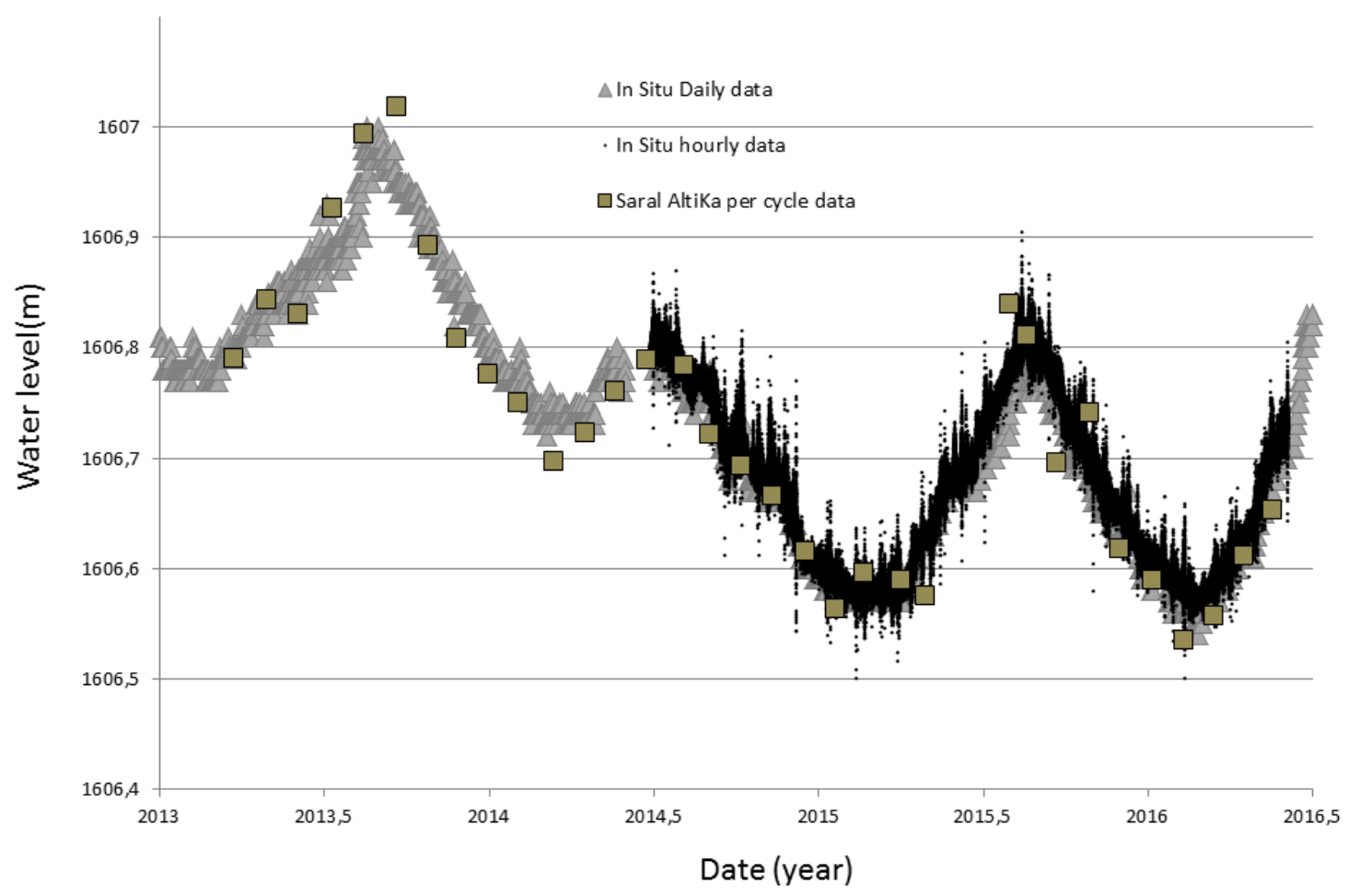

Figure 6. Water level of the lake Issykkul measured by SARAL/AltiKa, a radar and a tide gauge located on respectively east and north coast of the lake, delivering hourly and daily data. RMS of differences between SARAL/AltiKa and the in situ daily data is $3.5 \mathrm{~cm}$. 
For specific calculation of altimeter bias of AltiKa, a GPS survey of the track number 554 has been performed during a campaign done on 1 July 2014. The GPS vertical profile along this track is compared to individual measurements of the altimeters over the first 15 cycles using in situ measurements for all corrections:

- Wet and dry tropospheric delay using a permanent GPS and weather stations

- $\quad$ The GPS height antenna using a radar installed just below the GPS on the boat: see [16] for details.

- $\quad$ The in situ daily level changes for the correction of the hydrological signal from cycle 1 to cycle 15. 1 July 2014 is when the GPS survey was done and corresponds to cycle 14 .

- $\quad$ The GINS [18] software was used for the calculation of the GPS 3D coordinates in PPP (Precise Point Positioning) mode.

We then compare the GPS vertical coordinates along the track 554 with the individual measurements of the lake altitude above the ellipsoid using AltiKa measurements. We thus perform the calculation of the absolute bias using the ocean and the ice1-OCOG (Offset Centre Of Gravity) retrackers:

- With the ocean retracker, the water level bias, which is averaged along the track 554 and using the first 15 cycles of the satellite is given in Figure 7. The absolute bias obtained is: $-52 \pm 24 \mathrm{~mm}$.

- With ice1-OCOG retracker, the water level bias, which is averaged along the track 554 and using the first 15 cycles of the satellite, is given in Figure 8. The absolute bias obtained is: $+34 \pm 19 \mathrm{~mm}$.

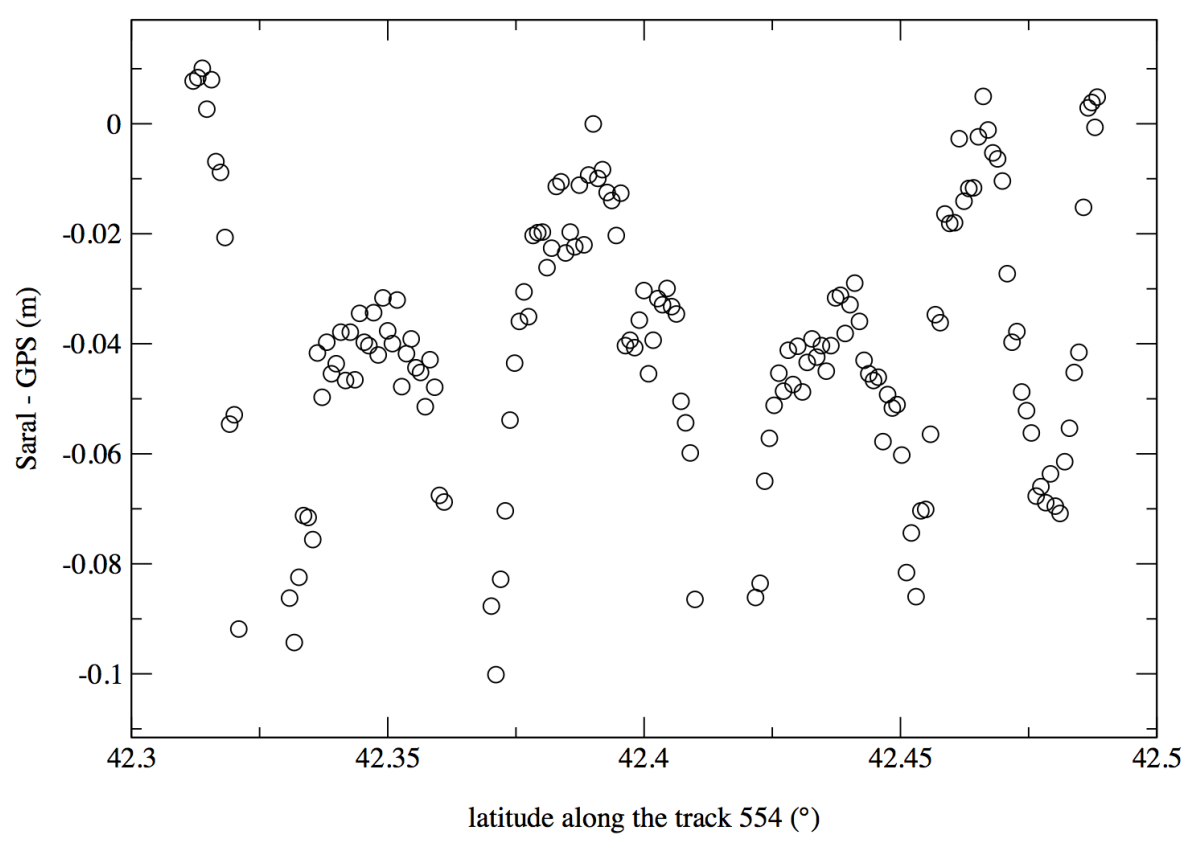

Figure 7. Differences between the GPS profiles and SARAL/AltiKa water altitude above the ellipsoid with ocean retracker at reference points corresponding to the GPS points along the SARAL/AltiKa track 554 . 


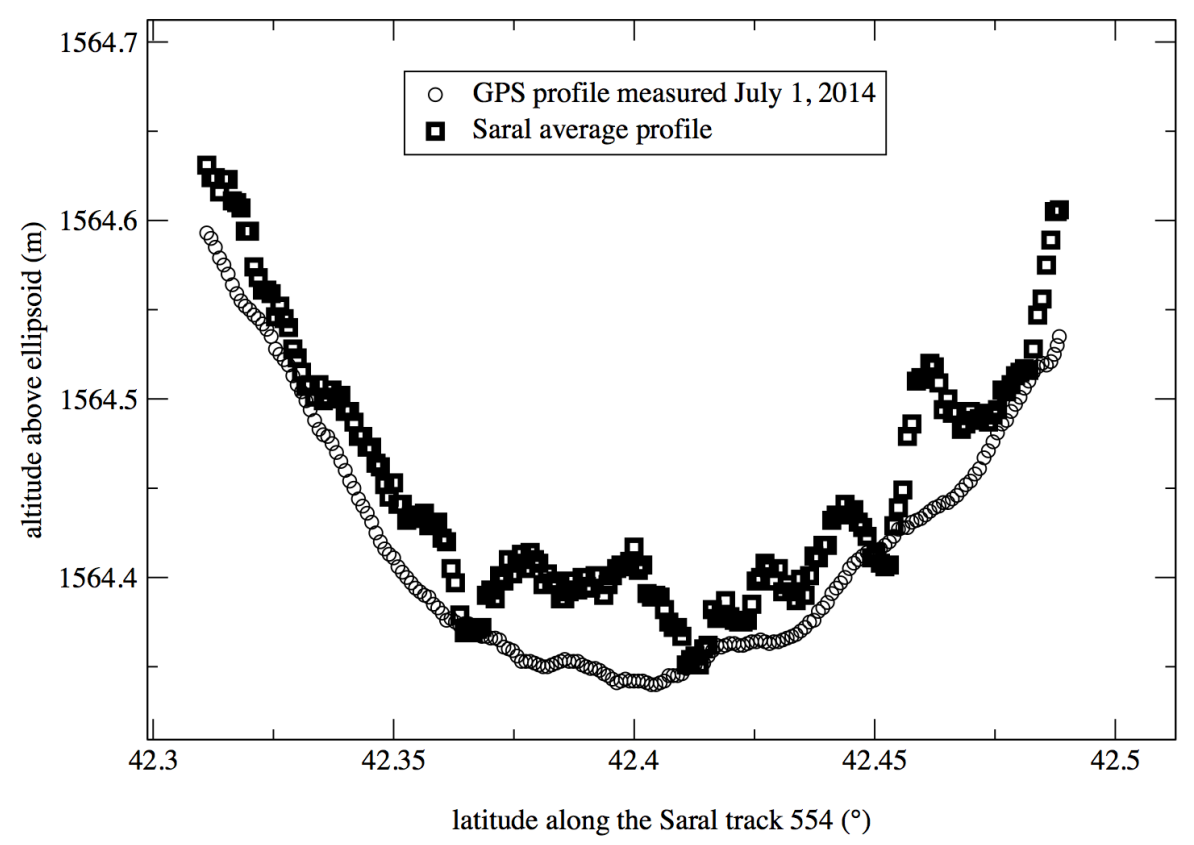

Figure 8. Vertical profiles along the track 554. The altimetry profile is an average over 15 first cycles at reference point corresponding to the GPS points of measurements. Ice1 retracker is represented.

\subsection{Regional Calibration of SARAL/AltiKa Sea Surface Height in Corsica, at Harvest and at Bass Strait}

In situ calibration of altimeter SSH is usually done at the vertical of a specific cal/val site by direct comparison of the altimeter data with the in situ data. Given that most of the in situ calibration sites (Harvest, Senetosa, Bass Strait and Gavdos) were specifically designed to be located under the TOPEX/Jason orbit, the classical absolute calibration technique can only be used for satellites using this orbit. The regional cal/val technique developed by Noveltis $[19,20]$ aims to assess the altimeter range bias both on satellite passes flying over the calibration site and on satellite passes located several hundreds of kilometres away (Figure 9). In particular, it enables the monitoring of altimetry missions that do not fly directly over the calibration sites, such as SARAL/AltiKa. In principle this technique extends the single site approach to a wider regional scale, thus reinforcing the link between the local and the global cal/val analyses.

The regional method is used to compute the SARAL/AltiKa altimeter biases at three historical TOPEX/Jason-suite calibration sites: the Corsican calibration sites of Senetosa and Ajaccio, the Californian site of Harvest and the Australian site of Bass Strait. These calibration sites are characterized by very different ocean variabilities, which leads to various strategies in terms of corrections for the altimeter $\mathrm{SSH}$.

In Corsica, the ocean variability (from few days to seasons) is rather low (about $50 \mathrm{~cm}$ on average), mainly governed by the wind and the atmospheric pressure variations, with low tidal amplitudes (about $20 \mathrm{~cm}$ ). However, the presence of small islands close to the sites of Ajaccio and Senetosa can have an impact on the quality of the altimeter SSH and the associated corrections, in particular the radiometer wet tropospheric correction. The wet tropospheric correction derived from the ECMWF (European Centre for Medium-Range Weather Forecasts) model is thus used to correct the SARAL/AltiKa SSH in Corsica. In addition, the altimeter and the in situ tide gauge observations are corrected using respectively the COMAPI regional tidal model (Coastal Modeling for Altimetry Product Improvement) [21] for the tides and a global hydrodynamic simulation provided by LEGOS for the DAC (Dynamic Atmospheric Correction) effects [22]. In Harvest and Bass Strait, the ocean variability is much higher than in Corsica (about $2.5 \mathrm{~m}$ ), with large tidal amplitudes (about $1.5 \mathrm{~m}$ ). The FES2004 global tidal model [23] and the global DAC simulation is used to correct the altimeter and 
the in situ observations at both sites. In addition, the radiometer-derived wet tropospheric correction is used to correct the altimeter SSH.

Figure 10 shows the crossover points considered for the computation of the regional SARAL/AltiKa bias estimates at each calibration site. In Harvest and Bass Strait, the number of selected crossover points is rather small in comparison to the number of available points. Large variability is observed in the bias estimates at those surrounding crossover points and they are discarded from the computation (see $[19,20]$ for details). Some previous work on the Envisat mission in Bass Strait [24] showed that using a more recent tidal model with higher resolution (FES2014 global tidal model, [25]) enables us to drastically reduce the variability at some of those points and to reintegrate them in the computation in this specific region. The mean regional bias estimates at each calibration site are given in Table 1. The standard deviation computed over the mean bias estimates at each crossover point is given in the last column. This information shows that the variability of the bias estimates over the considered crossover points is stable from one site to the other, in the order of $1 \mathrm{~cm}$. However, the mean bias estimates and the averaged standard deviation of the bias estimates strongly vary from one site to the other, with mean variability of about $60 \mathrm{~mm}$ in Harvest and Bass Strait, twice larger than in Corsica, which is directly linked to local conditions (open ocean with rough seas in Harvest and Bass Strait, sheltered harbours with low ocean variabilities in Corsica). Even after correcting the $30 \mathrm{~mm}$ offset in the Ajaccio tide gauge measurements (see Section 2.1.2) the $47 \mathrm{~mm}$ difference observed in the bias estimates between Ajaccio and Senetosa, is for the moment unexplained and need further investigation. However, the averaged SSH bias from Ajaccio and Senetosa is $61 \mathrm{~mm}$ and is close to the values found from the absolute calibration study (see Section 2.1.2). Further investigation is also needed to understand the $\sim 40 \mathrm{~mm}$ difference observed between the bias estimates in Corsica and the estimates in Harvest and Bass Strait. It is more than probable that high precision regional tidal models and dynamical atmospheric correction solutions would improve the computation of accurate altimeter and in situ sea surface heights in these regions.

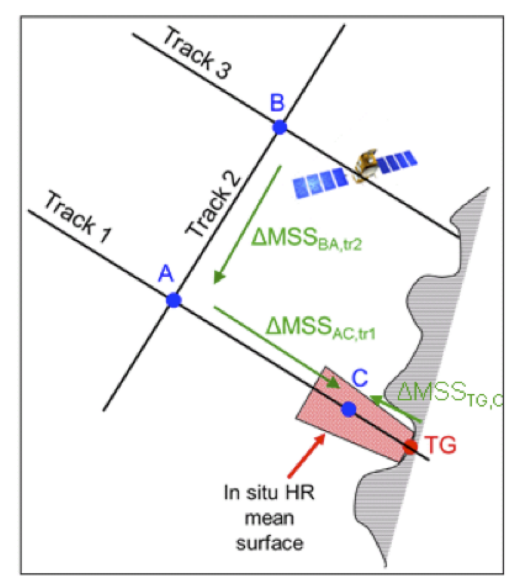

Figure 9. Generic diagram of the regional in situ calibration method. The points A and B represent the crossover points between, respectively, the satellite altimeter tracks 1 and 2, and the tracks 2 and 3 . The tracks can belong to different altimeter missions. The in situ high resolution mean surface is used to link the tide gauge (TG) measurements to the altimeter data, and the comparison is done at the point C, located on this surface (adapted from [20]). 

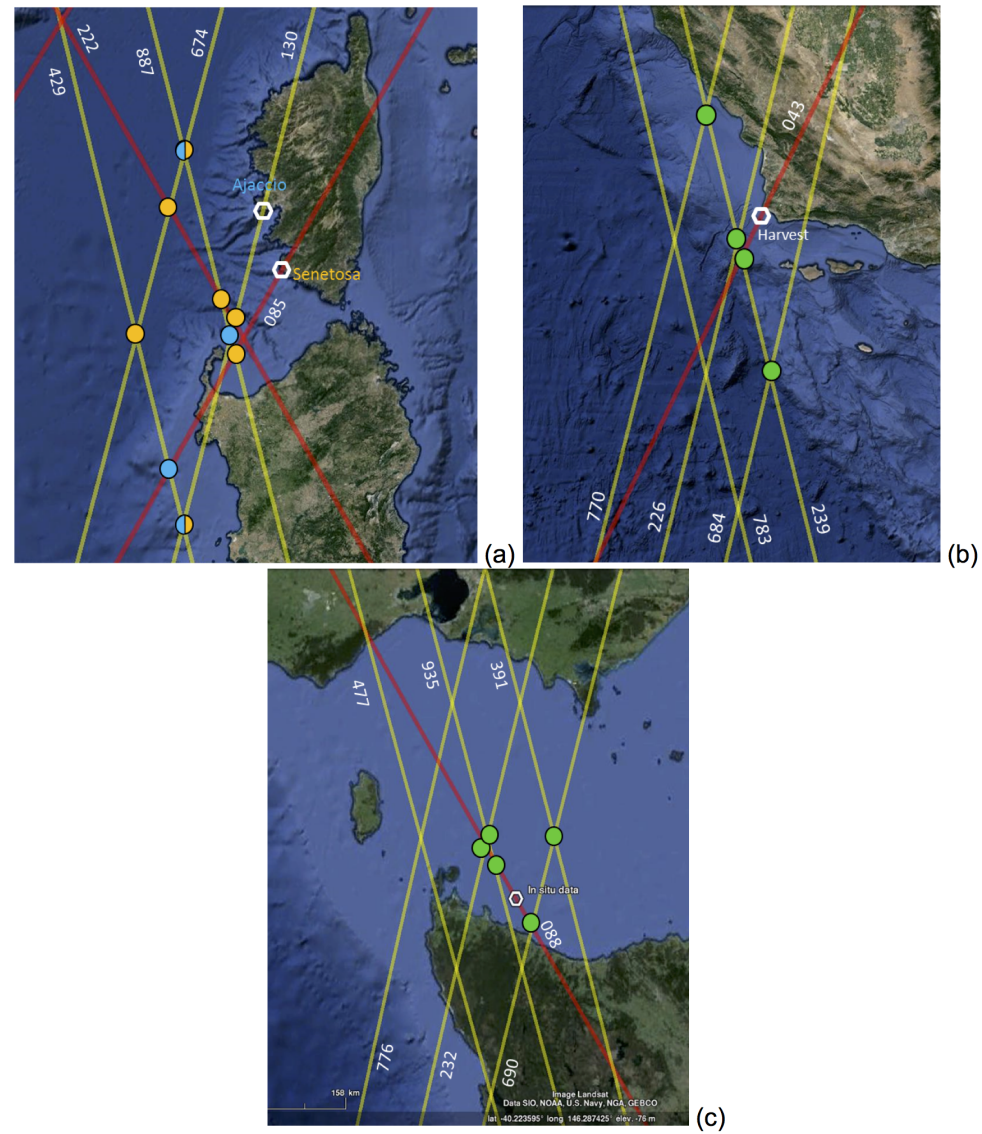

Figure 10. Altimeter crossover points used for the SARAL/AltiKa regional bias estimate in Corsica (a: Ajaccio in blue, Senetosa in orange), Harvest (b: green dots) and Bass Strait (c: green dots). The SARAL/AltiKa and Jason-2 grounds tracks are shown respectively in yellow and red.

Table 1. SARAL/AltiKa regional bias estimates at each site. In Bass Strait, the in situ data available for this study only covers the period until cycle 25 .

\begin{tabular}{cccccc}
\hline $\begin{array}{c}\text { SARAL/Altika Regional } \\
\text { Bias Estimates (mm) }\end{array}$ & $\begin{array}{c}\text { Mean } \\
(\mathbf{m m})\end{array}$ & $\begin{array}{c}\text { Std } \\
(\mathbf{m m})\end{array}$ & $\begin{array}{c}\text { Nb of } \\
\text { Cycles }\end{array}$ & $\begin{array}{c}\text { Nb of Xover } \\
\text { Points }\end{array}$ & $\begin{array}{c}\text { Std over the } \\
\text { Xover Points (mm) }\end{array}$ \\
\hline Senetosa (cycle 1-35) & $-84 \pm 5$ & 32 & 34 & 7 & 5 \\
Ajaccio (cycle 1-35) & $-37 \pm 6$ & 36 & 33 & 6 & 13 \\
Harvest (cycle 1-35) & $-19 \pm 12$ & 64 & 30 & 4 & 12 \\
Bass Strait (cycle 1-25) & $-22 \pm 11$ & 56 & 24 & 5 & 13 \\
\hline
\end{tabular}

\subsection{Global Validation of SARAL/AltiKa Sea Surface Height over Ocean}

Since the beginning, SARAL/AltiKa data shows a high quality and provides new information with respect to the previous missions [5]. At high latitude, thanks to its orbit reaching $82^{\circ}$, the Arctic Ocean and ice caps are better covered. Near the coast, measurements are more numerous and reliable [26] thanks to its high rate of $40 \mathrm{~Hz}$ (one point every $125 \mathrm{~m}$ along-track) and to its robust tracking mode (DIODE/Median, except for cycles 10 to 17 in autonomous DIODE mode). Furthermore, high frequency structures are better addressed, thanks to its Ka-band technology [27].

Its data availability is largely over the specification requirements, reaching $99.6 \%$ over oceans, Safe Hold Mode periods included, compared to $99.3 \%$ on Jason-2. Over other surfaces, the coverage is also very homogeneous as shown on Figure 11. Even the sensitivity of the Ka-band frequency to rain has less impact than expected. Indeed, only $5 \%$ of measurements may be not achieved due to rain rates $>1.5 \mathrm{~mm} / \mathrm{h}$ according to geographic areas [28]. 
SARAL/Altika

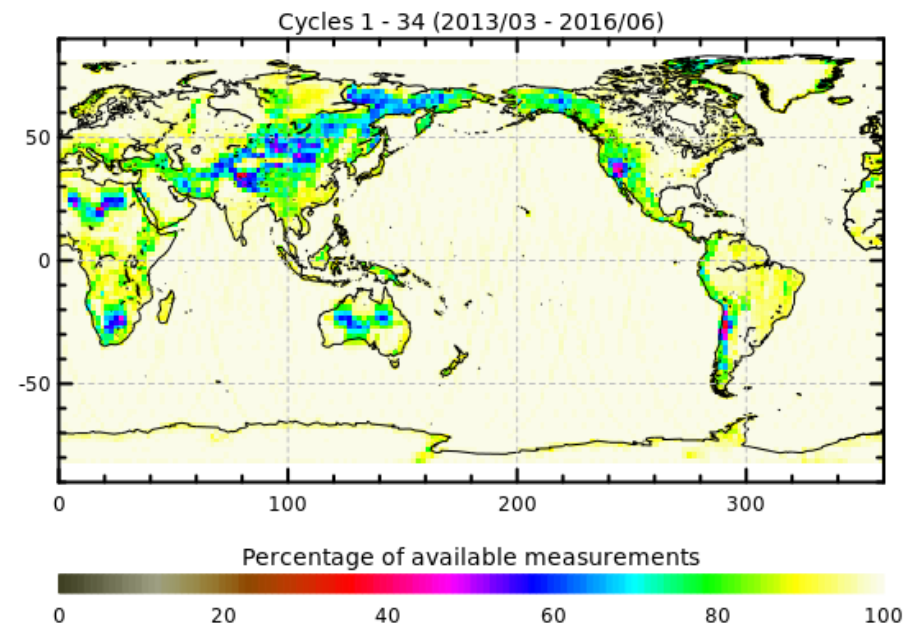

Figure 11. Map of the percentage of available measurements over land on SARAL/AltiKa's cycles 1 to 34.

The relative SSH bias compared to a zero reference of the TOPEX GMSL in 1993 (Global Mean Sea Level, CMEMS 2018 standards (Copernicus Marine Environment Monitoring Service)) is $-82.3 \mathrm{~mm}$ for SARAL/AltiKa, whereas Sentinel-3A stands for $-3.9 \mathrm{~mm}$, Jason-2 for $-18.5 \mathrm{~mm}$ and Jason-3 for $-47.3 \mathrm{~mm}$. Relative SSH bias and its evolution can also be derived from crossovers with a reference mission (such as Jason ones); even if not based exactly on the same length of the time series, results provided in [5] agree at the centimeter level with the ones presented here.

Its long-term stability as well, exceeds the mission requirements, featuring a very consistent mean sea level with respect to the reference record, derived from a combination of TOPEX/Jason-1/Jason-2 time series [29]. SARAL/AltiKa GMSL's shows a $4.8 \mathrm{~mm} /$ year evolution on this time period, thus keeping pace with Jason-2 (4.4 mm/year). It is a very satisfying statistic knowing that the time series for SARAL/AltiKa is still under 5 years which is the minimum period required to have a significant trend, see Figure 12.

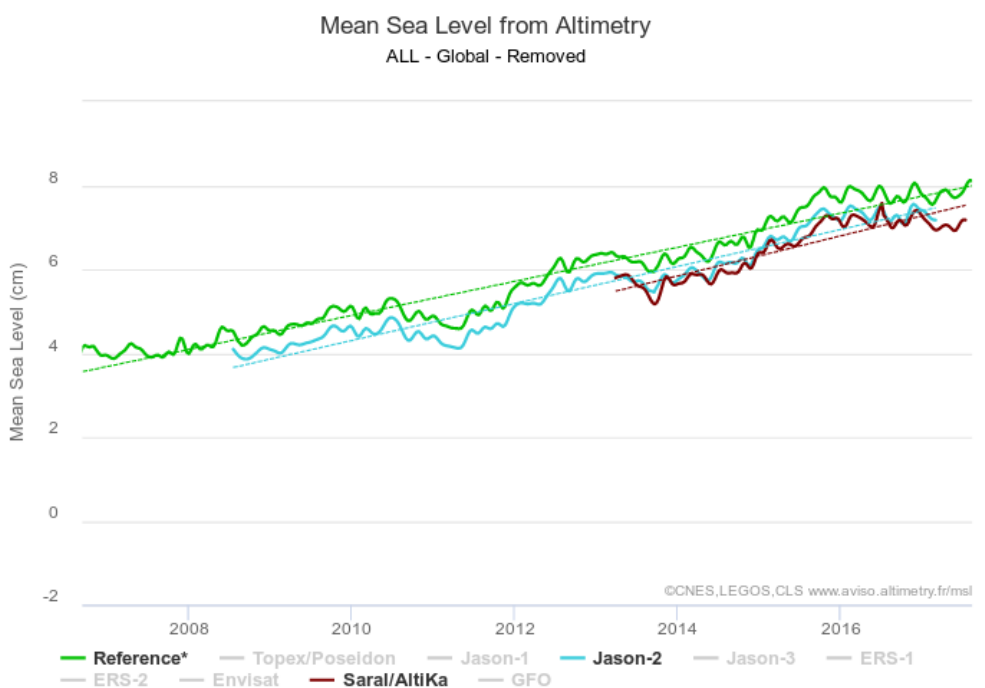

Figure 12. SARAL/AltiKa's Global Mean Sea Level (red) compared to Jason-2 (blue) and the reference one (green). 
As for crossovers analysis (see details in [5]), it demonstrates excellent performances, with $5.3 \mathrm{~cm}$ of standard deviation compared to $5.4 \mathrm{~cm}$ for Jason-2, using the radiometric correction [30]. This illustrates SARAL/AltiKa's very good skills to resolve mesoscale signatures.

Finally, SARAL/AltiKa's Ka-band frequency enables the resolution of small scales of ocean dynamics (mesoscale). Thanks to its higher rate of $40 \mathrm{~Hz}$ and a smaller and statistically more homogeneous footprint, its noise level is lower than Jason-2/3 (Figure 13). Provided the application of a fine editing (for $20 \mathrm{~Hz}$ measurements: based on the Sea Level Anomaly coherence of consecutives measurements) and a correction [31] dedicated to reduce correlated noise between altimeter range and Significant Wave Height (SWH), it does even better than delay-doppler altimetry missions such as Sentinel-3A. Smaller ocean scales are therefore observable notably around $35 \mathrm{~km}$ where the spectral "bump" [32] is clearly reduced compared to "standard" use of the data (see Figure 1 in [3] for comparison).

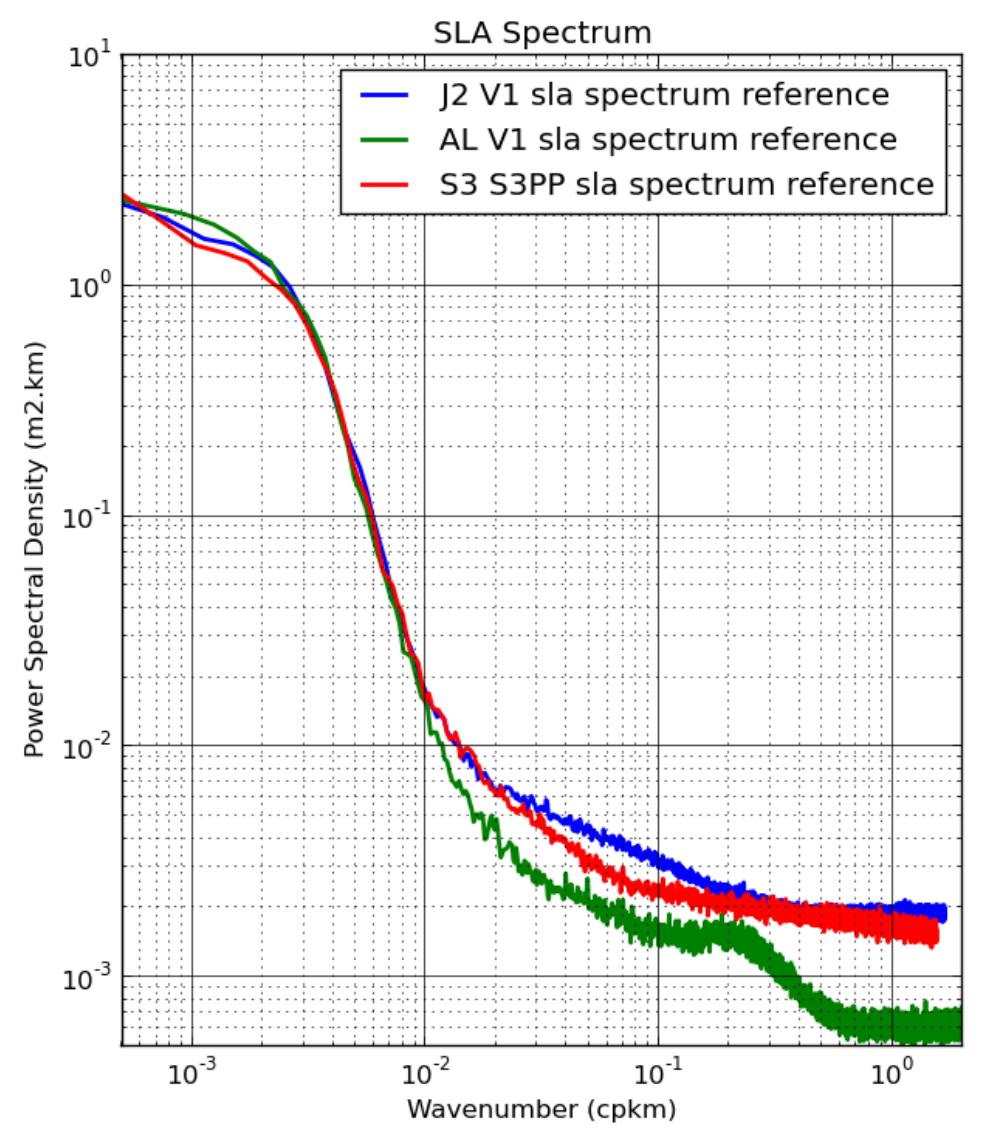

Figure 13. SARAL/AltiKa's SLA power spectrum (green) compared to Jason-2 (blue) and Sentinel-3A (red), with adapted editing and [31] correction for the three missions.

In conclusion, the SARAL/AltiKa mission performance remains excellent, compared to Jason-2, Jason-3 and Sentinel-3A, from fine scale ocean dynamics to long-term stability. And its quality will keep on improving, notably, thanks to several updates of geophysical corrections which are getting ready for the future reprocessing (GDR-E (Geophysical Data Record)) planned for 2018. The benefits of SARAL/AltiKa data to access the fine scale ocean dynamics are highlighted in our companion paper [3]. 


\section{Unique Contributions of Ka-Band Information in AltiKa Data}

The key feature of the altimetric payload has been the selection of Ka-band [27]. Using Ka-band avoids the need for a second frequency to correct for the ionosphere delay and eases the sharing of the antenna by the altimeter and the radiometer. The use of the Ka-band also allows the improvement of the range measurement accuracy in a ratio close to 2 (30 cm compared to $47 \mathrm{~cm}$ for Jason Ku-band) due to the use of a wider bandwidth and to a better pulse to pulse echo decorrelation. The higher pulse repetition frequency ( $4 \mathrm{KHz}$ compared with $2 \mathrm{KHz}$ on Jason-2) also permits a better along-track sampling of the surface. Moreover, the enhanced bandwidth ( $480 \mathrm{MHz}$ compared with $320 \mathrm{MHz}$ on Jason-2) enables a better resolution of the range. Finally, Ka-band antenna aperture is reduced, which limits the pollution within useful ground footprint. The known effect of rain on the Ka-band was such to put some uncertainty on the full availability of data in some regions. In fact, the larger sensitivity to small rates of rain was found to be less constraining than expected and in counterpart provides access to low rains climatology [28].

Apart from the improved accuracy and resolution for the liquid water surfaces (ocean and inland waters), the fact that AltiKa altimeter operates in Ka-band, which is higher than the previous frequencies, offer new paths of investigation. The penetration depth in snow is theoretically reduced from around $10 \mathrm{~m}$ in $\mathrm{Ku}$-band to less than $1 \mathrm{~m}$ in Ka-band, such that the volume echo originates from the near subsurface. Second, the sharper antenna aperture leads to a narrower leading edge that reduces the impact of the ratio between surface and volume echoes of the height retrieval. Moreover, the volume echo in the Ka-band results from the near subsurface layer and is mostly controlled by ice grain size, unlike the Ku-band [33].

This section gives some illustrations of the unique characteristics of AltiKa instrument that offer unique contributions in fields that where not fully foreseen. Section 3.1 will give insights of the increase of resolution and data availability close to the coasts. Section 3.2 will focus on the Ka-band contribution for altimetry over snow and ice. Section 3.3 will study the rain sensitivity and finally Section 3.4 will give an original use of Ka-band measurements for studying the soil moisture.

\subsection{Power Spectrum Density Analysis of SSH Signal from SARAL/AltiKa and Jason-2 (1 Hz) over Bay of Bengal}

Indian coasts are vulnerable to high waves and rough sea conditions particularly during the pre- and post-monsoon seasons due to the presence of extreme atmospheric events such as cyclones. Unfortunately, wave models are still not mature enough to predict these waves due to the lack of accurate initial conditions and correct physical parameterizations. With the availability of altimeter data, assimilation of these data in numerical models is often found beneficial in improving the accuracies of the model predictions. One very significant promising development, particularly for the coastal regions, is the SARAL/AltiKa mission carrying onboard altimeter in the Ka-band and thus offering high spatial resolution suitable for coastal studies and assimilation in coastal wave models.

Tracks in the full Bay of Bengal region for the concurrent period of SARAL/AltiKa and Jason-2 (March 2013-July 2016) were used and $1 \mathrm{~Hz}$ Sea Surface Height (SSH) spectrum of both altimeters was studied. The Figure 14 shows the SSH spectrums of both the altimeters. Difference is noteworthy at wave length less than $50 \mathrm{~km}$. The higher slopes in the wave lengths below $50 \mathrm{~km}$ shows the spectrum for SARAL/AltiKa have lesser noise than Jason-2 in this region. The power spectrum in the mesoscale region $\left(50 \mathrm{~km}-250 \mathrm{~km}\right.$ ) is also fitted with power law $\mathrm{a}^{*} \mathrm{k}^{b}$ ( $\mathrm{k}$ is wavenumber). The values of $\mathrm{b}$ for AltiKa is -1.96 as compared to $b=-1.79$ for Jason-2. Above $50 \mathrm{~km}$ wave length, both SARAL/AltiKa and Jason are comparable to each other. Also the approachability towards the coast has been studied using the SARAL/AltiKa based ISRO Space Applications Center (SAC) coastal product and the Coastal and Hydrology Altimetry product (PISTACH) product from Jason-2. Figure 15a shows the 20-Hz SWH from Jason-2 towards the coast and Figure 15b shows 40-Hz SWH from SARAL/AltiKa. Clearly the SARAL/AltiKa based coastal product provides more valid data in proximity to the coast that will help to improve the coastal models. 


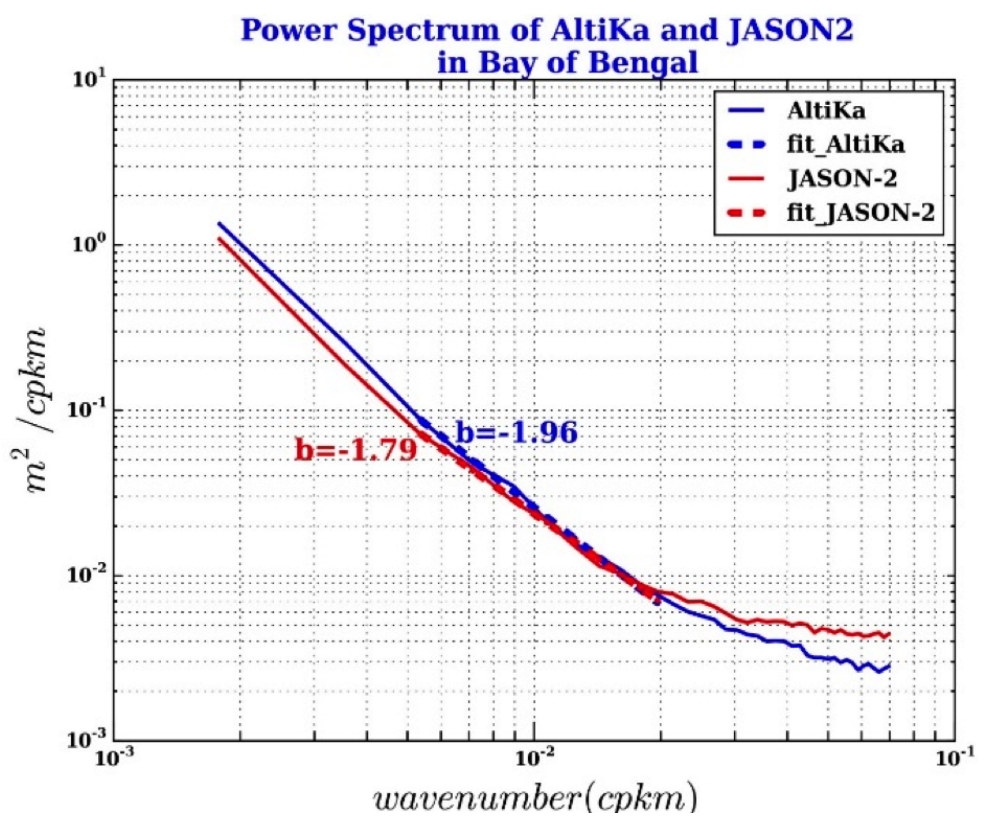

Figure 14. The power spectra of sea surface heights from SARAL/AltiKa and Jason-2 in Bay of Bengal. Green line represents $(1 / 50 \mathrm{~km})$.
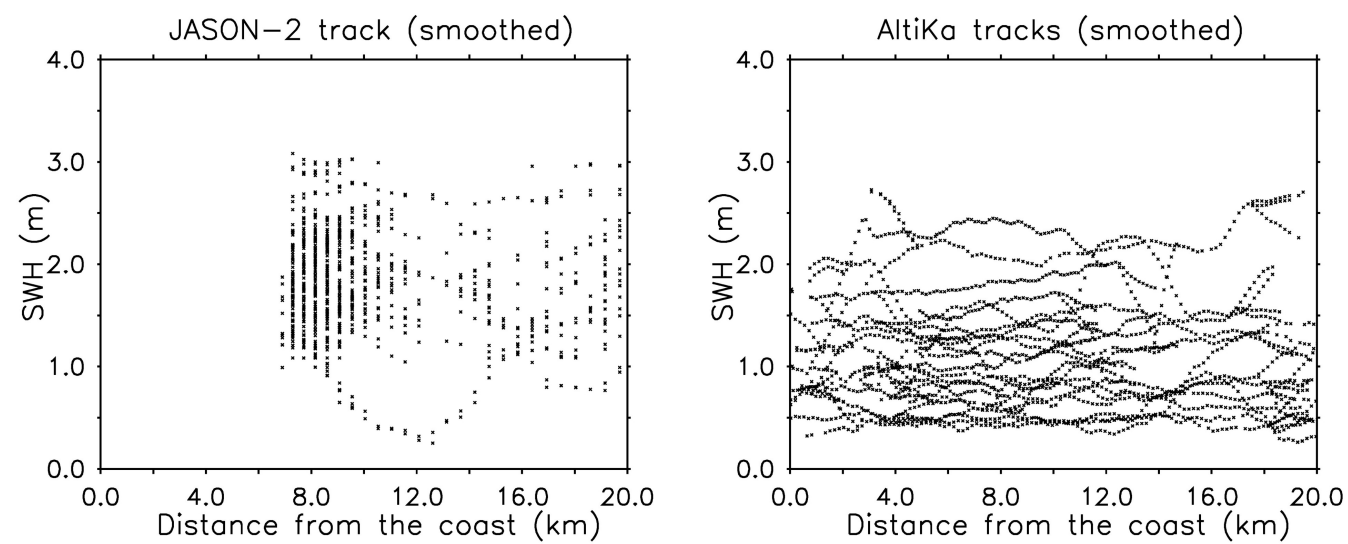

Figure 15. SWH from Jason-2 PISTACH product (left) and SAC coastal product (right) based on AltiKa data.

\subsection{Complementarity between Ku and Ka Measurements over Ice Sheet Surfaces}

Exploiting Ka frequency properties over land ice or sea ice is of particular interest to better assess the level of surfaces covered by ice or snow. Comparing measurements in $\mathrm{Ku}$ and $\mathrm{Ka}$ frequencies allows us to understand and quantify the penetration properties of the radar waves. Over water surfaces, $\mathrm{Ku}$ and $\mathrm{Ka}$ signals reflect at the air/water interface. It is commonly understood that in presence of snow or ice, the radar wave penetrates the ice pack if its wavelength is larger than the snow grain size (typically $0.5 \mathrm{~mm}$ but grain size depends on the temperature (snow metamorphism) and snow accumulation). According to [34], higher temperatures cause the snow grains to grow quickly, whereas higher accumulation rate causes them to slowly grow. $\mathrm{Ku}$ - and Ka-band wavelengths are respectively $2.21 \mathrm{~cm}$ and $0.84 \mathrm{~cm}$. The factors between signal wavelength and grain size are respectively 44 and 17 in $\mathrm{Ku}$ - and Ka-bands. For a given wavelength, according to Mie theory [35], the scattering coefficient is conversely proportional to the radar wavelength at a power of 4 . From Ku- to Ka-band, the scattering coefficient consequently increases by a factor 55 . This leads to a penetration depth over 
snow surface between $0.1 \mathrm{~m}$ and $0.3 \mathrm{~m}$ in Ka-band [36]. Analysis performed on the altimeter signal acquired in $\mathrm{Ku}$ - and Ka-bands over the Antarctic ice sheet are consistent with this assumption.

To illustrate this theoretical introduction, we represent in Figure 16, the different penetration effects in $\mathrm{Ku}$ - and Ka-bands by comparing mean waveforms computed over ocean (SWH $=1 \mathrm{~m}$ $\pm 20 \mathrm{~cm}$ and similar epochs) and at a cross-over over Lake Vostok [37]. This lake in Antarctic is known to be quite perfectly flat, avoiding all effects induced by surface slopes (that can be different in $\mathrm{Ku}$ - and Ka-bands due to the different antenna gain patterns of the two missions). Over ocean, for SARAL/AltiKa (Ka-band) and Sentinel-3A (Ku-band in Pseudo-Low Resolution Mode), 1498 and 377 individual waveforms have been aggregated. Over Lake Vostok, for SARAL/AltiKa and Sentinel-3A, 1763 and 359 individual waveforms have been aggregated. We must note that waveforms have been artificially aligned to be compared.
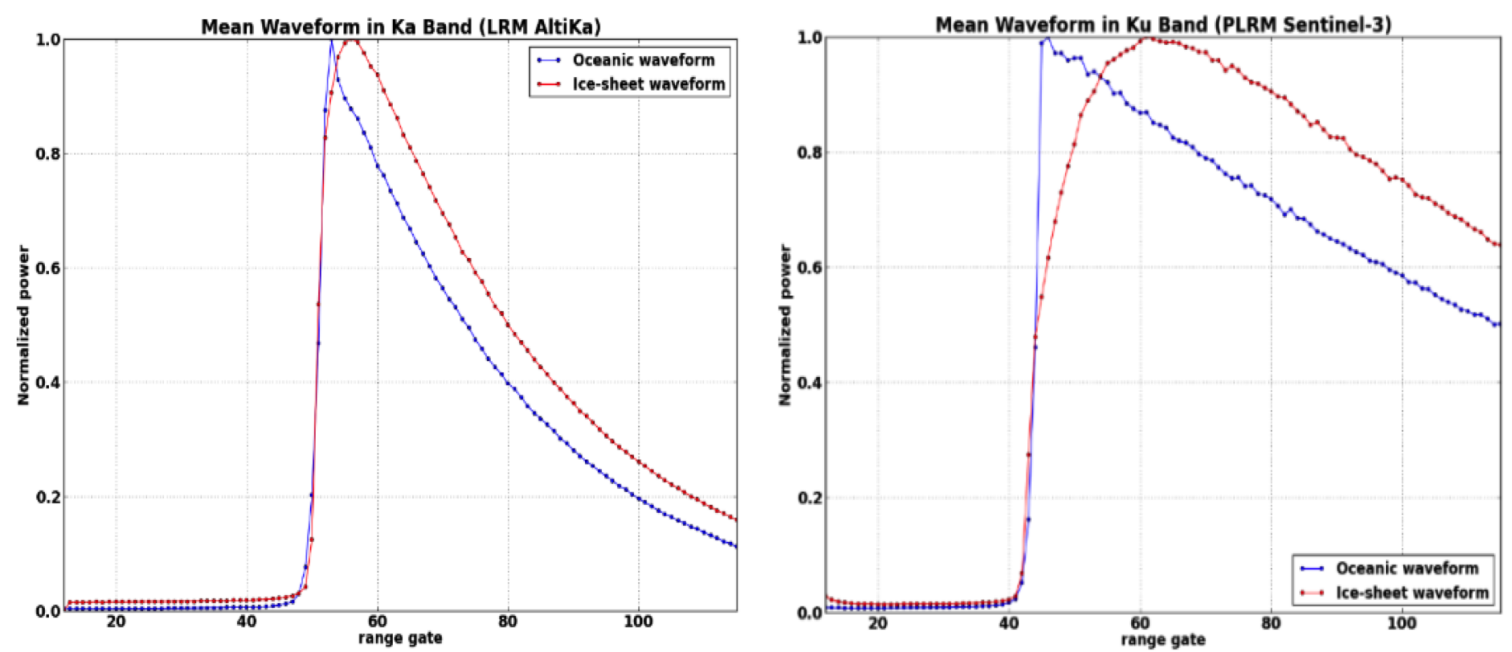

Figure 16. Mean SARAL/AltiKa (left) and Sentinel-3A (right) waveforms over ocean (blue) and Lake Vostok (red).

It appears on the left plot of Figure 16 that ocean and land ice leading edges are quite identical except for the very last points of the leading edge. Additional energy appears on the trailing edge samples for ice returns. This clearly indicates that the radar signal has been backscattered in the snow pack. However, considering that the distribution of energy in the leading edge is similar over ocean and over land ice, we can assume that an unique reflective surface is responsible for the main reflection (as for ocean) and that a retracking processing will provide the range corresponding to the distance between the satellite and this reflective surface. This surface can be assumed to be at the air/snow interface.

The plot on the right of Figure 16 shows that in Ku-band, returns are completely different over ocean and land ice. Clearly, the red echo can be considered as the summation of different contributions coming from different layers inside the snow pack, each contribution being attenuated depending on the absorption characteristics of each layer. In these cases, determining a range indicating the position of the main reflection (its distance from the radar) is very hard. If a threshold empirical retracker is used, the value of the threshold arbitrarily determines the reflective surface inside the snowpack.

For a better comparison of $\mathrm{Ku}$ and Ka measurements over Lake Vostok, waveforms in both bands are superimposed in Figure 17. The waveform acquired in Synthetic Aperture Radar (SAR) mode (Sentinel-3A, Ku-band) has been added (in red). As for SARAL/AltiKa, Sentinel-3A SAR mode mean echo over Lake Vostok presents a leading edge not impacted by penetration effects. 

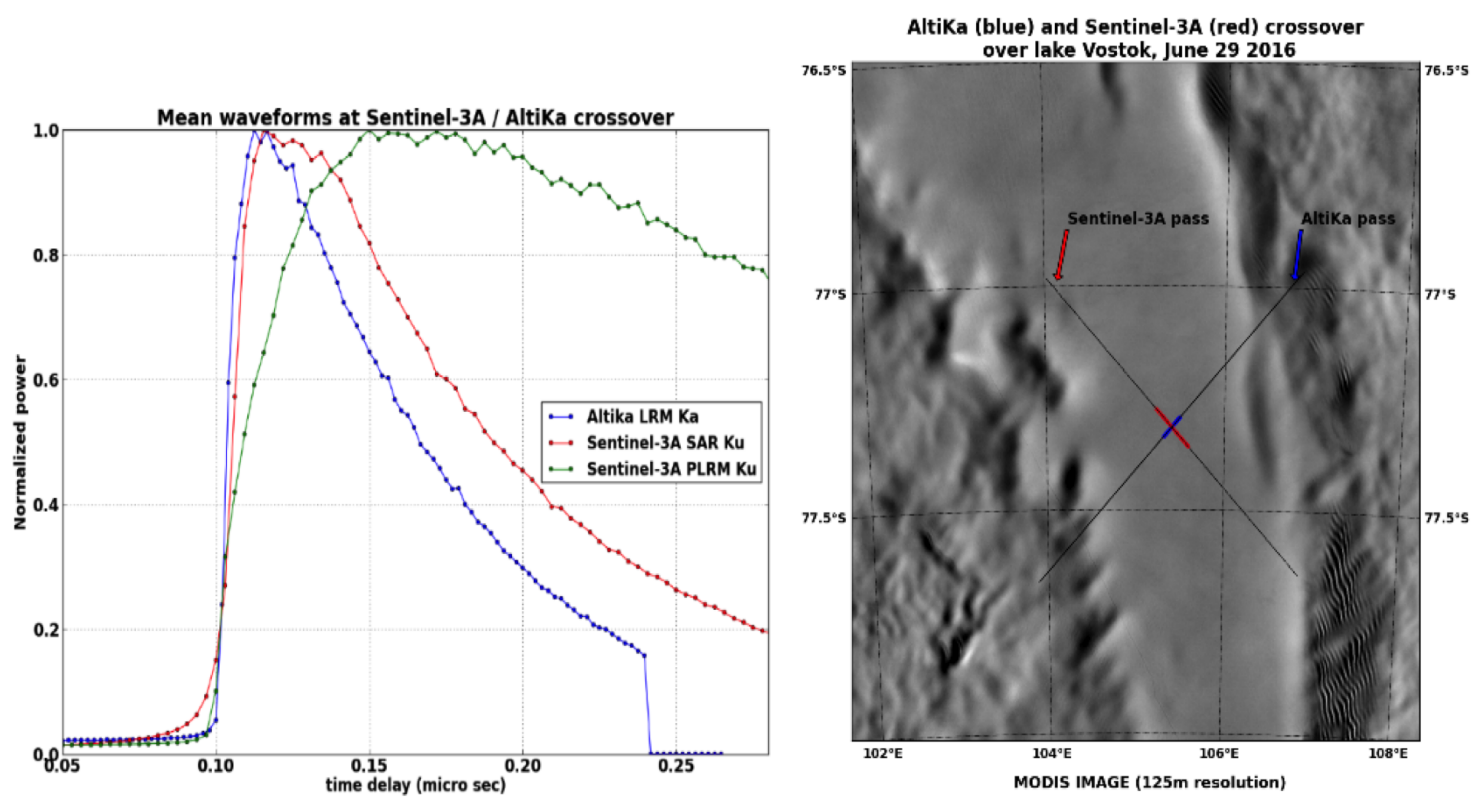

Figure 17. Left: Mean SARAL/AltiKa (blue) and Sentinel-3A (SAR in red, P-LRM in green) waveforms at a cross-over between SARAL/AltiKa and Sentinel-3A over Lake Vostok. Right: MODIS image of Lake Vostok with SARAL/AltiKa and Sentinel-3A tracks locations.

This analysis illustrates the complementarity between $\mathrm{Ku}$ and $\mathrm{Ka}$ measurements over ice sheet surfaces and the potential relevant information that could be retrieved by combining them. Of particular interest is the snow thickness that could be derived from the exploitation of the Ku and Ka waveform shapes, in particular their trailing edges.

Analysis of SARAL/AltiKa measurements over ice sheet have not only brought a new insight of the radar measurements of the snowpack but also encourage the development of new algorithms able to derive new parameters such as snow or ice pack properties. Scientific applications based on Ka-band unique characteristics and complementarity with Ku-band over ice sheet, icebergs and sea ice are developed in [3].

\subsection{Impact of Rain on SARAL/AltiKa Measurements, a New Opportunity to Observe and Study the Rainfall Climatology}

Since the first developments of the SARAL/AltiKa mission, one of the major concerns has been the Ka-band sensitivity to atmospheric conditions, and especially to atmospheric liquid water (both rain and clouds). Hence, the instrument power and gain have been optimized in order to maximize the Signal to Noise Ratio (SNR) and to minimize atmospheric attenuation issues [27]. As a result, the data loss over ocean is lower than anticipated $(<0.1 \%)$ and the SNR is higher than the preflight expected value (14 dB) thanks to margins taken in the altimeter link budget (see details in [27]). An example of an AltiKa SNR map over ocean is provided in Figure 18 for cycle number 110, showing values varying from 18 to $32 \mathrm{~dB}$. The altimeter link budget is thus excellent and allows a full data coverage over ocean.

Despite the very low number of lost data, the high sensitivity of the Ka-band to atmospheric liquid water (ten times larger than in Ku-band) impacts the altimeter waveform shape. AltiKa echoes are attenuated and distorted by rain events of heavy clouds [38-40], as shown in Figure 19a. The waveform amplitude is not only strongly attenuated but its shape is distorted, especially on the trailing edge part of the waveform. The example shown in Figure 19a is collocated to WindSat and SSMIS-F16/F17 rainfall rate measurements indicating a rain rate of about $4.5 \mathrm{~mm} / \mathrm{h}$ during this event. 

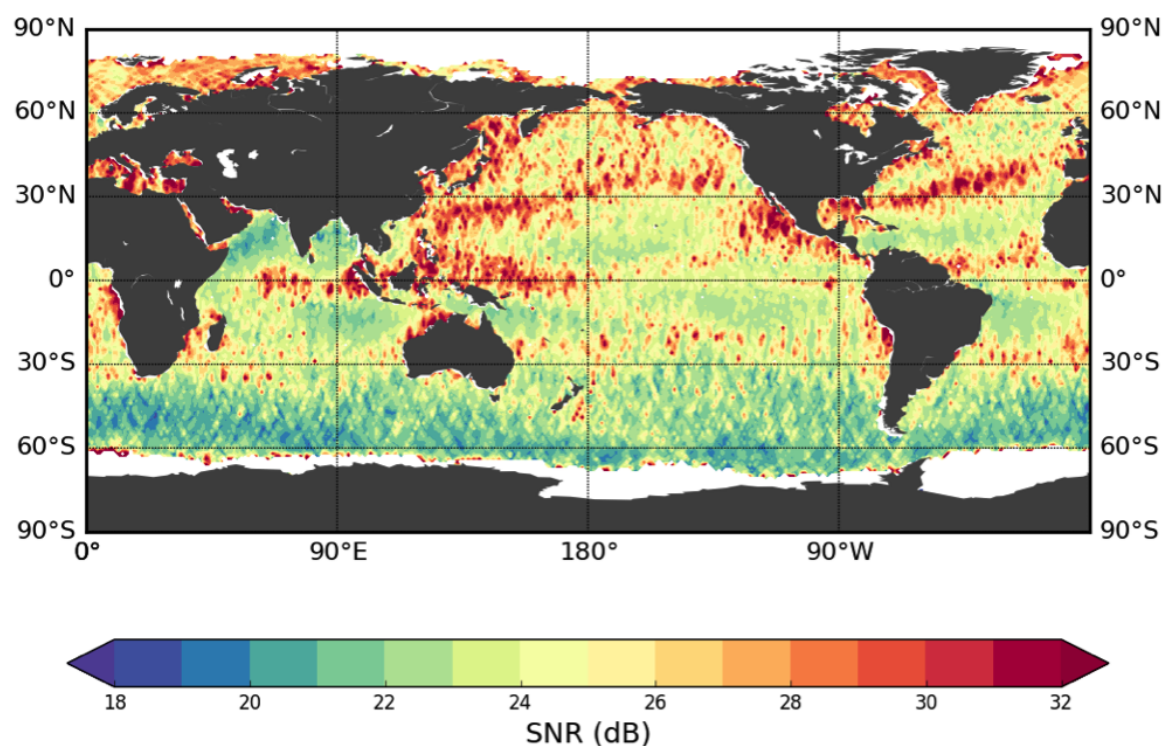

Figure 18. Map of Signal to Noise Ratio computed from standard MLE-4 estimates over ocean for cycle number 110 (from 2017/06/19 to 2017/07/24).

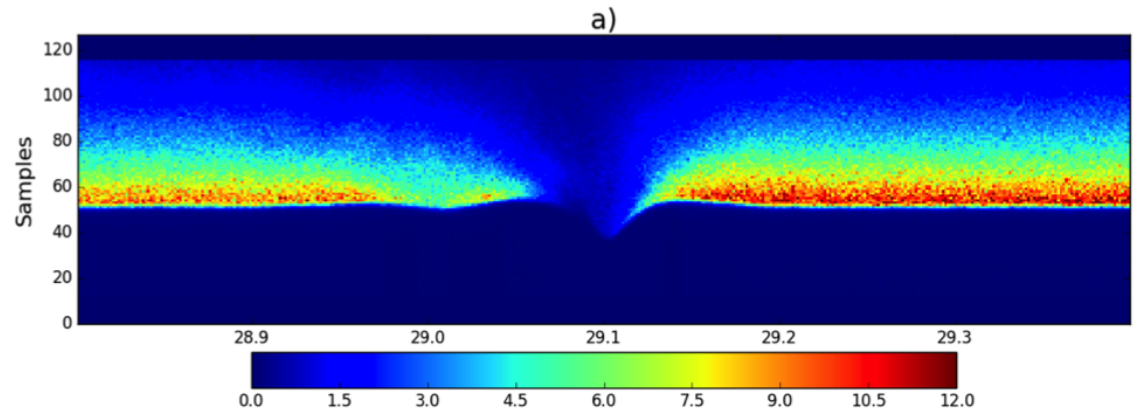

b)

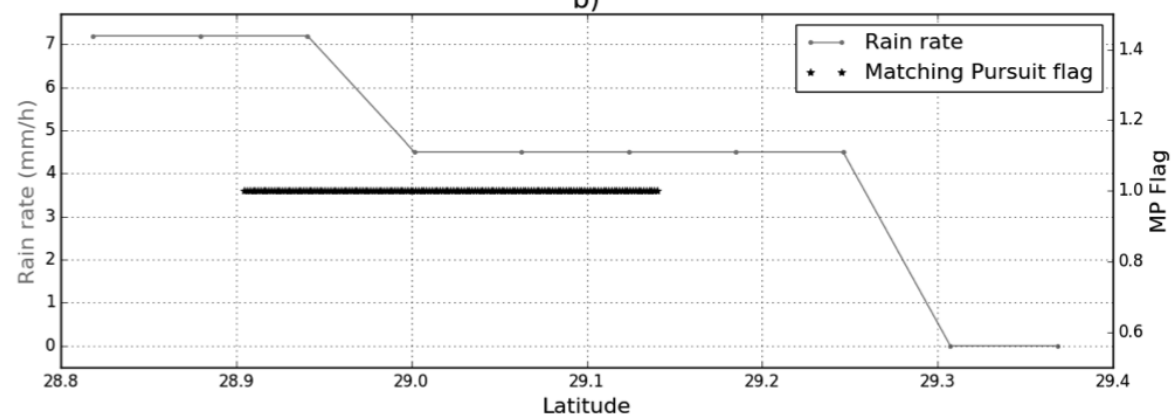

Figure 19. (a) AltiKa waveforms corrected from Automatic Gain Control during a rain event, pass 121 cycle 5; (b) collocated rainfall rate from SSMI and WindSat measurement in grey and Matching Pursuit flag in black [41].

Even if measurements are not lost during a rain event, the resulting waveform corruption may degrade the retracker performances and the geophysical estimates [42]. Indeed, operational ocean retrackers implemented in the ground segment are not designed to correctly process rain waveforms: these retrackers consider that the altimeter waveform footprint contains homogeneous backscattering properties. This is clearly not the case during rain events. As a result, the noise on each geophysical estimate increases when SARAL/AltiKa is overflying a rain cell. Impact of rain pollution on the range noise is illustrated in Figure 20. The collocation between SARAL/AltiKa and the WindSat/SSMIS measurements has been performed accounting for a maximum time delay of 1 hour. A clear rain 
rate dependency of the altimeter range noise (about $0.35 \mathrm{~cm} / \mathrm{mm} / \mathrm{h}$ ) can be observed. The other geophysical estimates (significant wave height and backscattering coefficient) are impacted as well. Recent developments (in particular the "Adaptive" retracker) have shown very promising results to deal with such corrupted echoes [43].

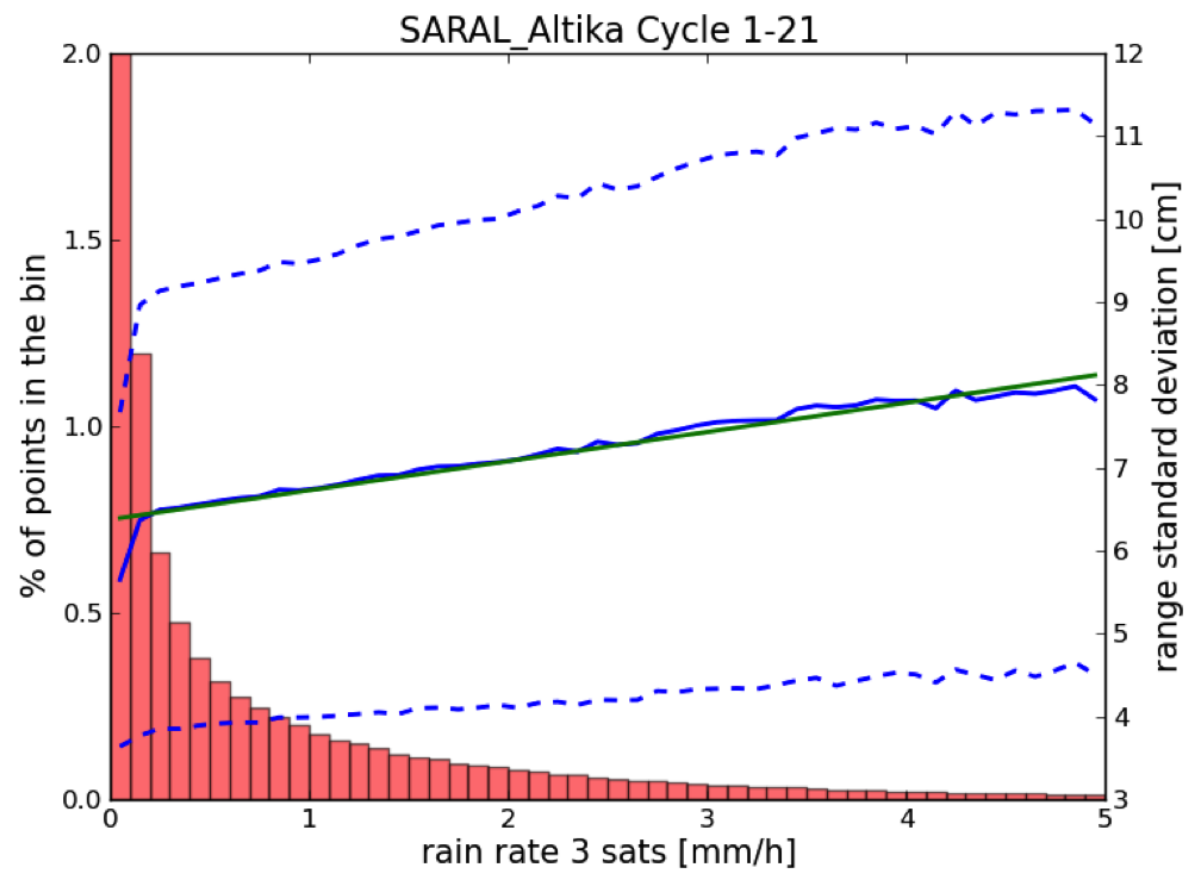

Figure 20. Variations of range std against rain rate. Please note that the first bin corresponding to dry measurements is truncated on the plot as it contains more than $70 \%$ of the measurement points. The plain blue line is the mean of the range standard deviation and the dashed blue lines represent the standard deviation for this mean. The green line is a linear regression of the mean (plain blue line).

The editing of altimeter data impacted by rain has been largely addressed in previous studies [44-46] and different methods exist to identify rain measurements. In the SARAL/AltiKa ground processing, the Matching Pursuit algorithm has been selected to flag rain data. This algorithm is based on the analysis of the short scale variations of the off-nadir angle estimate to identify rain cells in the SARAL/AltiKa measurements [41]. The performances of this algorithm have been assessed in [28] and show that the Matching Pursuit algorithm combined with the radiometer Integrated Liquid Water Content (ILWC) $>0.1 \mathrm{~kg} / \mathrm{m}^{2}$ provide a good rain flag. A map of $1 \mathrm{~Hz}$ flagged points is shown in Figure 21 illustrating the geographical distribution of the near $10 \%$ flagged measurements. As expected, most of the flagged points over ocean are located in the Intertropical Convergence Zone which reflects the global distribution of precipitations [47]. The comparison of the rain flag performances with WindSat and SSMIS-F16/F17 rainfall rates has shown acceptable performances but studies have been performed to improve and simplify rain flagging based on continuous wavelet transform. Results have been presented in [48].

Flagging SARAL/AltiKa measurements corrupted by rain presents a new opportunity to observe and study the rainfall climatology, seasonal and inter-annual variability. Moreover, the link between the signal attenuation and the rainfall rate can be exploited to extract valuable information on rain events. On-going studies seek to exploit Ka-band measurements to derive rain rate information, coupling them with the brightness temperature measurements provided by the radiometers for climatological monitoring. 

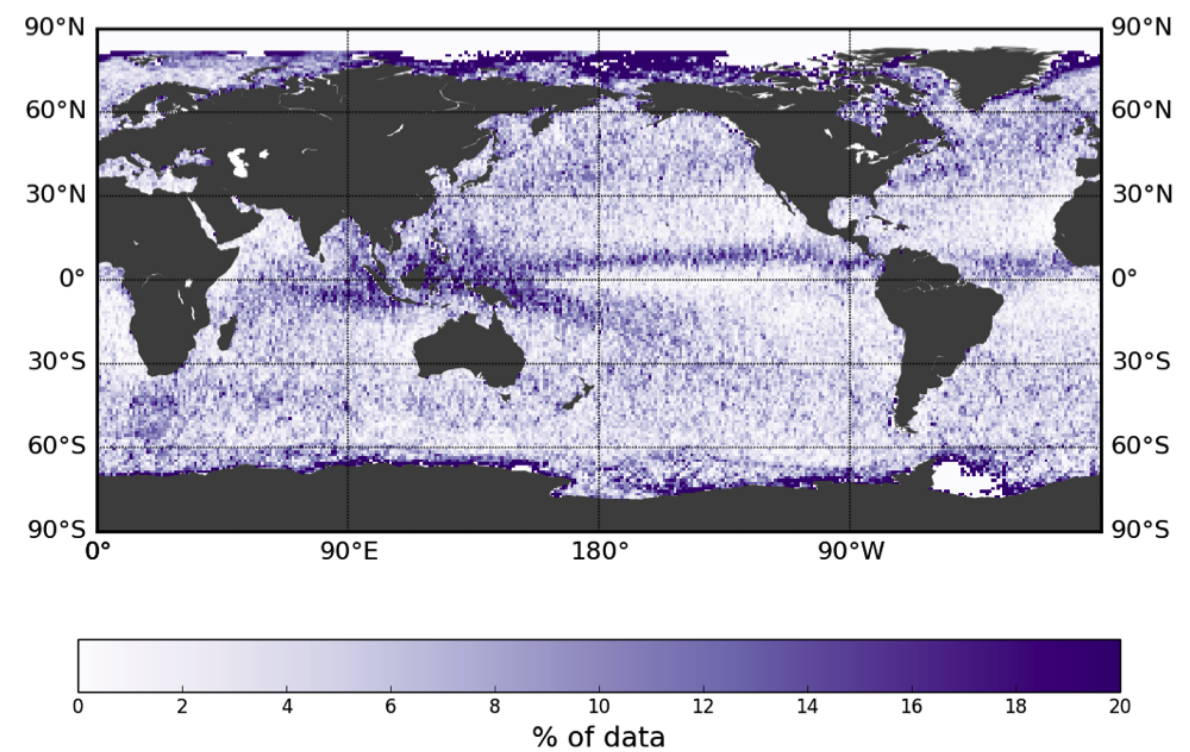

Figure 21. Percentage of $1 \mathrm{~Hz}$ flagged samples using the operational MP algorithm for which the ILWC $>0.1 \mathrm{~kg} / \mathrm{m}^{2}$ for 1 year (cycles 100 to 110 ).

\subsection{Relationship between Surface Soil Moisture and Radar Altimetry Backscattering Coefficients}

Spatial and temporal variations of radar altimetry backscattering coefficients were related to the dynamics of surface properties. In semi-arid areas, soil moisture drives several surface processes including soil organic matter mineralization [49], vegetation productivity [50], land surface fluxes [51] and land surface atmosphere interactions [52]. A first inversion of the surface soil moisture (SSM) from the Ice-1 derived backscattering coefficients at Ku-band from Envisat RA-2 data was performed over Sahelian savannahs in the Gourma region of Mali [53]. Due to the lower sensitivity of nadir-looking altimeters to vegetation cover compared with side-looking SAR and scatterometers [54], higher correlation was found between in-situ SSM measurements and altimetry ( $R=0.88,[53])$ than with SAR $(R=0.85,[55])$ and scatterometer $(R=0.63,[56])$ backscattering coefficients over the sandy sites of the same semi-arid study area. Using the 16 first available cycles of the SARAL/AltiKa mission, the correlation is 0.88 between radar altimetry Ice- 1 derived backscattering coefficients at Ka-band and level-3 SSM products derived from the Soil Moisture and Ocean Salinity satellite (SMOS) passive microwave observations over Sahelian savannahs [57]. The results obtained were generally better than the ones obtained using 3.5 times more numerous backscattering coefficients at $\mathrm{Ku}$ and $\mathrm{C}$-bands from Jason-2 during the same observation period or the ones obtained using backscattering coefficients at $\mathrm{Ku}$ and S-bands from Envisat during its whole observation period (and comparing them to level-3 SSM products derived from AMSR-E) or passive microwave observations [57]. Time series of altimetry backscattering coefficients (obtained using Ice-1 retracking algorithm) at Ka-band from SARAL/AltiKa and $\mathrm{Ku}$ and $\mathrm{C}$ bands from Jason-2 are presented in Figure 22 from February 2013 to May 2016 over Sudano-Sahelian savanahs. This period corresponds to the 35 cycles of SARAL/AltiKa on its nominal orbit (and to cycles 169 to 291 of Jason-2). The backscattering level during the dry season decreases as the frequency increases-around $22.5 \mathrm{~dB}$ at C-band, $17 \mathrm{~dB}$ at Ku-band, and between $5 \mathrm{~dB}$ and $6 \mathrm{~dB}$ at Ka-band - whereas the amplitude of variations increases with the frequency-up to $10 \mathrm{~dB}$ at C-band, $20 \mathrm{~dB}$ at Ku-band and $30 \mathrm{~dB}$ at Ka-band. The larger dynamic of the backscattering coefficient at Ka-band during the rainy season is a strong advantage to accurately monitor the time-variations of SSM in semi-arid areas. Correlation coefficients between backscattering coefficients and SSM from SMOS (derived using the approach from [58]) were computed on the common period of availability of the two datasets, from February 2013 to May 2015. Due to the rapid response of SSM to rainfall-strong increase after a rainfall event followed by a fast decrease due to evaporation-in semi-arid environments, 
correlation were re-estimated applying a three-day smoothing window to limit the effect of the difference of acquisition time between altimeters and SMOS. Very similar results are obtained for both ascending and descending tracks:

(i) $\mathrm{R}=0.80$ and 0.79 at Ka-band for SARAL/AltiKa tracks 0001 and 0846 respectively,

(ii) $\mathrm{R}=0.58$ and 0.54 at $\mathrm{Ku}$-band for Jason-2 tracks 046 and 161 respectively,

(iii) $\mathrm{R}=0.64$ and 0.65 at $\mathrm{C}$-band for Jason-2 tracks 046 and 161 respectively.

As the backscattering coefficient is linearly related to SSM over sand, better estimates of SSM can be expected from the inversion of altimetry backscattering coefficient at Ka-band than at other frequency bands commonly used in altimetry. In spite of the low temporal resolution of the SARAL/AltiKa mission with its repeat-period of 35 days, altimetry-derived SSM at Ka-band would be useful for the monitoring of the seasonal variations of this key variable along the altimeter tracks at high spatial resolution ( $\sim 165 \mathrm{~m}$ using the high-frequency $40 \mathrm{~Hz}$ data) and could be used for the calibration and validation of land-surface models and low resolution active (scatterometry) and passive (radiometry) microwave-based products. The characteristics of the backscattering coefficient at Ka-band illustrated in this study is also used to study the snow and ice state and important scientific results are given in [3].
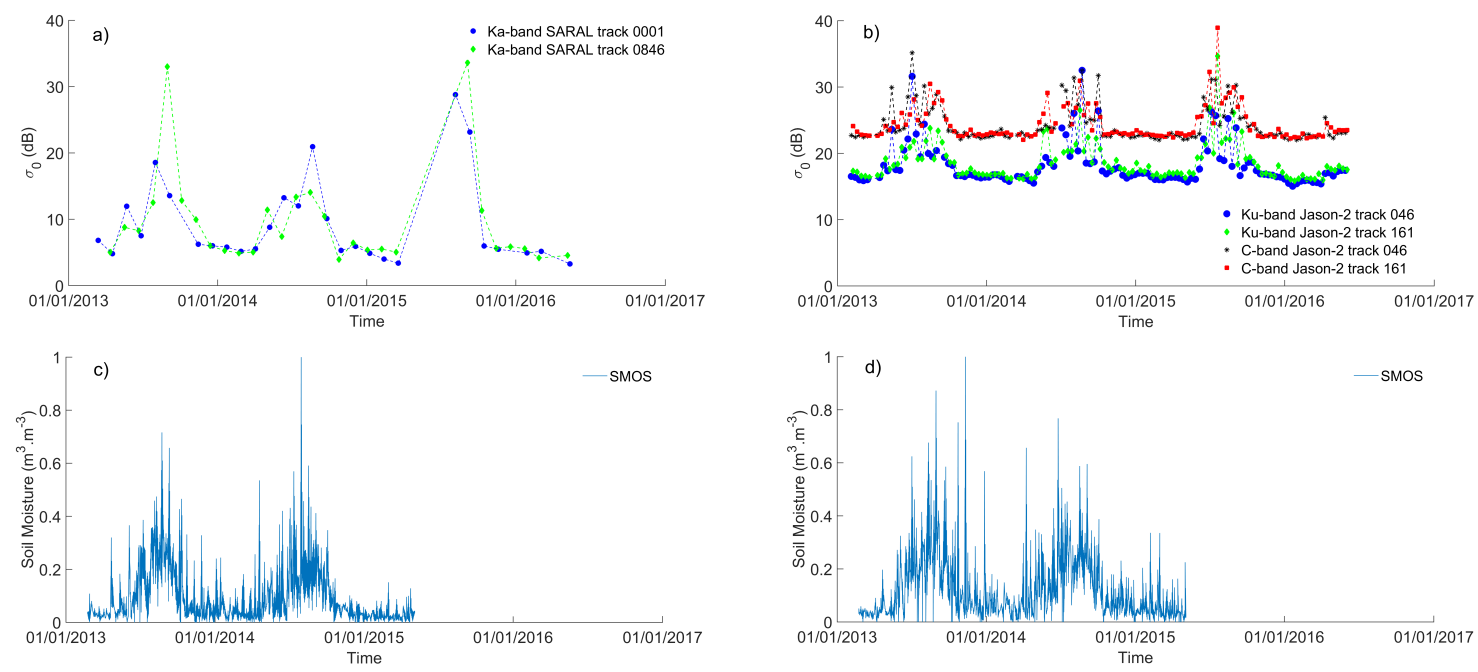

Figure 22. Time-series of backscattering coefficient (dB) for (a) SARAL/AltiKa (Ka-band) 0001 (blue) and 0846 (green) tracks and (b) Jason-2 (Ku and C-bands) 046 (blue and black) and 161 (light green and red), of volumetric soil moisture (m3.m-3), from SMOS (blue) at SARAL/AltiKa (c) and Jason-2 (d) sites.

\section{Conclusions}

Altimetry has been dominated by the Ku-band since the beginning and strong fears about a possible degradation by using Ka-band had limited the studies about launching a mission embarking on such technology. Vincent et al. [36] demonstrated the feasibility of such an altimeter but also importantly the need of higher resolution altimetry to address one of the most problematic features of ocean circulation, the mesoscale eddies and fronts. These features are essential to understanding the dynamics of ocean circulation on all space and time scales and theoretical studies of the cascade of energy over scales from 100-1000 km have always suffered from the lack of high-resolution observations. From [36] a Ka-band altimeter technology looked to be able to provide higher resolution to help answering these key issues. Selecting the Ka-band allows a larger bandwidth (480 MHz), which provides a vertical resolution of $0.3 \mathrm{~m}$ instead of $0.5 \mathrm{~m}$ in Ku-band. With such a resolution, the altimeter is close to a beam limited one: there is no 'plateau' in the echo as in Ku-band, since it strongly attenuates shortly after the leading edge, due to the small antenna aperture. This greatly 
reduces the pollution of 'land gates' into 'ocean gates', when considering land-sea transition areas. Moreover, due to the smaller antenna beamwidth, the Brown echo has a sharper shape in Ka-band than what is obtained with conventional Ku-band altimeters. Finally, the shorter decorrelation time of sea echoes at Ka-band also enables to double the number of independent echoes per second compared with Ku-band altimeters, allowing high frequency measurements ( $40 \mathrm{~Hz}, 20 \mathrm{~Hz}$ for Ku-band).

SARAL/AltiKa mission is the realization of the [36] study and in this paper we show that the quality of its measurements meets and generally exceeds the expectation of the visionary designers of this mission. Firstly, one of the main result is probably the fact that the AltiKa data quality and accuracy are met at a similar level whatever the water surfaces and whatever the scale (Section 2). This is demonstrated using global, regional or local methods and based on comparisons with various external data (in situ, other altimetric missions). The precision is at least at the same level or even better than for Ku-band for the open-oceans but improves substantially the along-track resolution (e.g., Figure 13 or Figure 14). These results will continue to improve with the reprocessing in 2018 with upgraded standards (GDR-E). Moreover, the characteristics of the AltiKa instrument allows to observe smaller water surfaces with equivalent precision and are of very great interest for coastal and inland waters studies [3]. The benefits of this increase of precision and resolution are highlighted through Science Applications of SARAL/Altika data [3]. Apart of these great achievements in term of precision and resolution, the characteristics of the altimeter and the Ka-band offer unique contributions in fields that where not fully foreseen. Before launch, concerns were raised about the sensitivity of the Ka-band to rain events, leading to missing and invalid measurements. However, in practice, the SARAL/AltiKa data return is remarkably high with few missing data (e.g., Figures 11 and 18). In fact, the sensitivity of Ka-band measurements to rain may also lead to a way of estimating very light rainfall over the oceans, for which we dramatically lack of information and which could lead to a great improvement of our knowledge of the oceanic rain climatology. Another specificity of the Ka-band is that electromagnetic wave penetration effects are minimized, which is particularly important over continental ice surfaces. From $\mathrm{Ku}$ - to Ka- bands, the scattering coefficient is increased by a factor 55: volume scattering is then being clearly dominant over surface scattering and gives information on snow or ice pack properties. Inversely, the radar wave extinction is also increased, leading to a penetration depth over the snow surface between $0.1 \mathrm{~m}$ and $0.3 \mathrm{~m}$ (versus 2 to $10 \mathrm{~m}$ in $\mathrm{Ku}$-band). The altimetric observation and height restitution thus correspond to a thin subsurface layer and give complementary information than the one given historically by the Ku-band (see Section 3.2 and [3]). Finally, the spatial and temporal variations of Ka-band backscattering coefficients that are related to the dynamics of surface properties, show valuable information for studying snow and ice state but also surface soil moisture (e.g., Section 3.4). This last field of studies is at his infancy but results presented in this paper are clearly encouraging.

With the upcoming Surface Water \& Ocean Topography (SWOT) mission embarking on a Ku-band nadir altimeter and a Ka-band interferometer (KaRIN) and the phase 0 of a new cryosphere satellite mission (bi-frequency altimeter in Ku- and Ka-band) that is currently studied by CNES and ESA, it is more than likely that SARAL/AltiKa Ka-band altimetric mission will continue to help preparing these missions but also help to understand $\mathrm{Ku}$-band better.

Acknowledgments: The SARAL/AltiKa mission is an achievement of a very fruitful cooperation between ISRO and CNES. The contribution of EUMETSAT to data distribution is also strongly appreciated. We acknowledge the support of all the Investigators, PIs and Co-Is, of the SARAL/AltiKa Mission. Most of the studies performed by the French authors have been conducted and financed thanks to Centre National d'Etudes Spatiales (CNES), Centre National de la Recherche Scientifique (CNRS), and French Ministry of Research. The altimetry data used in Section 3.4 were made available by "Centre de Topographie des Océans et de l'Hydrosphère" (CTOH)—https://ctoh.legos.obs-mip.fr/. The SMOS data were obtained from the "Centre Aval de Traitement des Données SMOS" (CATDS), operated for the "Centre National d'Etudes Spatiales" (CNES, France) by IFREMER (Brest, France)-https://www.catds.fr/sipad/.

Author Contributions: Pascal Bonnefond and Jacques Verron coordinated the whole paper. K. N. Babu designed the study, analyzed the data and wrote the Section 2.1.1. Pascal Bonnefond and Olivier Laurain designed the study, analyzed the data and wrote the Section 2.1.2. Jean-François Crétaux and Muriel Bergé-Nguyen designed 
the study, analyzed the data and wrote the Section 2.1.3. Mathilde Cancet designed the study, analyzed the data and wrote the Section 2.2 while Pascal Bonnefond, Bruce J. Haines, Olivier Laurain and Christopher Watson provided the data and contributed to the writing and analysis. Annabelle Ollivier and Pierre Prandi designed the study, analyzed the data and wrote the Section 2.3. Aditya Chaudhary and Rashmi Sharma designed the study, analyzed the data and wrote the Section 3.1. Pierre Thibaut and Jérémie Aublanc designed the study, analyzed the data and wrote the Section 3.2. Jean-Christophe Poisson, Pierre Prandi and Pierre Thibaut designed the study, analyzed the data and wrote the Section 3.3. Frédéric Frappart designed the study, analyzed the data and wrote the Section 3.4. All the other co-authors helped in the analysis and paper writing.

Conflicts of Interest: The authors declare no conflict of interest.

\section{References}

1. Verron, J.; Sengenes, P.; Lambin, J.; Noubel, J.; Steunou, N.; Guillot, A.; Picot, N.; Coutin-Faye, S.; Sharma, R.; Gairola, R.M.; et al. The SARAL/AltiKa altimetry satellite mission. Mar. Geod. 2015, 38, 2-21, doi:10.1080/01490419.2014.1000471.

2. Verron, J.; Picot, N. Preface. Mar. Geod. 2015, 38, 1, doi:10.1080/01490419.2015.1052711.

3. Verron, J.; Bonnefond, P.; Aouf, L.; Birol, F.; Bhowmick, S.A.; Calmant, S.; Carret, A.; Conchy, T.; Crétaux, J.F.; Dibarboure, G.; et al. The benefits of the Ka-band as evidenced from the SARAL/AltiKa altimetric mission: Scientific applications. Remote Sens. 2017, under review.

4. Church, J.; Clark, P.; Cazenave, A.; Gregory, J.; Jevrejeva, S.; Levermann, A.; Merrifield, M.; Milne, G.; Nerem, R.; Nunn, P.; et al. Climate change 2013: The physical science basis. Contribution of Working Group I to the fifth assessment report of the intergovernmental panel on climate change. In Sea Level Change; Cambridge University Press: Cambridge, UK; New York, NY, USA, 2013; Chapter 13.

5. Prandi, P.; Philipps, S.; Pignot, V.; Picot, N. SARAL/AltiKa global statistical assessment and cross-calibration with Jason-2. Mar. Geod. 2015, 38, 297-312, doi:10.1080/01490419.2014.995840.

6. Ablain, M.; Philipps, S.; Picot, N.; Bronner, E. Jason-2 global statistical assessment and cross-calibration with Jason-1. Mar. Geod. 2010, 33, 162-185, doi:10.1080/01490419.2010.487805.

7. Bonnefond, P.; Haines, B.; Watson, C. Coastal altimetry. In In Situ Calibration and Validation: A Link from Coastal to Open-Ocean Altimetry; Springer: Berlin/Heidelberg, Germany, 2011; Chapter 11, pp. 259-296, ISBN 978-3-642-12795-3.

8. Mertikas, S.P.; Daskalakis, A.; Tziavos, I.N.; Vergos, G.; Fratzis, X.; Tripolitsiotis, A. First calibration results for the SARAL/AltiKa altimetric mission using the gavdos permanent facilities. Mar. Geod. 2015, 38, 249-259, doi:10.1080/01490419.2015.1030052.

9. Bonnefond, P.; Desai, S.; Haines, B.; Leuliette, E.; Picot, N. Regional and Global CAL/VAL for Assembling a Climate Data Record Summary. In Proceedings of the Ocean Surface Topography Science Team Meeting, Miami, Florida, 2017. Available online: https://tinyurl.com/ycu32zeo (accessed on 9 January 2018).

10. Babu, K.N.; Shukla, A.K.; Suchandra, A.B.; Kumar, S.V.V.A.; Bonnefond, P.; Testut, L.; Mehra, P.; Laurain, O. Absolute calibration of SARAL/AltiKa in Kavaratti during its initial Calibration-validation phase. Mar. Geod. 2015, 38, 156-170, doi:10.1080/01490419.2015.1045639.

11. Bonnefond, P.; Exertier, P.; Laurain, O.; Guillot, A.; Picot, N.; Cancet, M.; Lyard, F. SARAL/AltiKa absolute calibration from the multi-mission Corsica facilities. Mar. Geod. 2015, 38, 171-192, doi:10.1080/01490419.2015.1029656.

12. Bonnefond, P.; Laurain, O.; Exertier, P.; Boy, F.; Guinle, T.; Picot, N.; Labroue, S.; Raynal, M.; Donlon, C.; Féménias, P.; et al. Calibrating SAR SSH of sentinel-3A and CryoSat-2 over the Corsica facilities. Remote Sens. 2018, 10, 92, doi:10.3390/rs10010092.

13. Crétaux, J.F.; Calmant, S.; Romanovski, V.; Shabunin, A.; Lyard, F.; Bergé-Nguyen, M.; Cazenave, A.; Hernandez, F.; Perosanz, F. An absolute calibration site for radar altimeters in the continental domain: Lake Issykkul in Central Asia. J. Geod. 2009, 83, 723-735, doi:10.1007/s00190-008-0289-7.

14. Crétaux, J.F.; Calmant, S.; Romanovski, V.; Perosanz, F.; Tashbaeva, S.; Bonnefond, P.; Moreira, D.; Shum, C.K.; Nino, F.; Bergé-Nguyen, M.; et al. Absolute Calibration of Jason Radar Altimeters from GPS Kinematic Campaigns over Lake Issykkul. Mar. Geod. 2011, 34, 291-318, doi:10.1080/01490419.2011.585110.

15. Crétaux, J.F.; Bergé-Nguyen, M.; Calmant, S.; Romanovski, V.; Meyssignac, B.; Perosanz, F.; Tashbaeva, S.; Arsen, A.; Fund, F.; Martignago, N.; et al. Calibration of Envisat radar altimeter over Lake Issykkul. Adv. Space Res. 2013, 51, 1523-1541, doi:10.1016/j.asr.2012.06.039. 
16. Cretaux, J.F.; Bergé-Nguyen, M.; Calmant, S.; Djamangulova, N.; Satylkanov, R.; Lyard, F.; Perosanz, F.; Verron, J.; Samine Montazem, A.; Le Guilcher, G.; et al. Absolute calibration / validation of the altimeters on sentinel-3A and Jason-3 over the lake Issykkul. Remote Sens. 2017, under review.

17. Arsen, A.; Crétaux, J.F.; del Rio, R.A. Use of SARAL/AltiKa over Mountainous Lakes, Intercomparison with Envisat Mission. Mar. Geod. 2015, 38, 534-548, doi:10.1080/01490419.2014.1002590.

18. Marty, J.C.; Loyer, S.; Perosanz, F.; Mercier, F.; Bracher, G.; Legresy, B.; Portier, L.; Capdeville, H.; Fund, F.; Lemoine, J.M.; et al. GINS: The CNES/GRGS GNSS scientific software. In Proceedings of the 3rd International Colloquium Scientific and Fundamental Aspects of the Galileo Programme, ESA Proceedings WPP326, Copenhagen, Denmark, 31 August-2 September 2011; Volume 31.

19. Jan, G.; Ménard, Y.; Faillot, M.; Lyard, F.; Jeansou, E.; Bonnefond, P. Offshore Absolute Calibration of space-borne radar altimeters. Mar. Geod. 2004, 27, 615-629, doi:10.1080/01490410490883469.

20. Cancet, M.; Bijac, S.; Chimot, J.; Bonnefond, P.; Jeansou, E.; Laurain, O.; Lyard, F.; Bronner, E.; Féménias, P. Regional in situ validation of satellite altimeters: Calibration and cross-calibration results at the Corsican sites. Adv. Space Res. 2013, 51, 1400-1417, doi:10.1016/j.asr.2012.06.017.

21. Cancet, M.; Lux, M.; Pénard, C. COMAPI: New Regional Tide Atlases and High Frequency Dynamical Atmospheric Correction. In Proceedings of the Ocean Surface Topography Science Team Meeting, Lisbon, Portugal, 2010. Available online: https: / / tinyurl.com/y98xedyq (accessed on 9 January 2018).

22. Carrère, L.; Lyard, F. Modeling the barotropic response of the global ocean to atmospheric wind and pressure forcing-Comparisons with observations. Geophys. Res. Lett. 2003, 30, 1275.

23. Lyard, F.; Lefevre, F.; Letellier, T.; Francis, O. Modelling the global ocean tides: Modern insights from FES2004. Ocean Dyn. 2006, 56, 394-415, doi:10.1007/s10236-006-0086-x.

24. Cancet, M.; Watson, C.; Haines, B.; Bonnefond, P.; Lyard, F.; Laurain, O.; Guinle, T. Regional CALVAL of Jason-2 and SARAL/AltiKa at Three Calibration Sites. In Proceedings of the Ocean Surface Topography Science Team Meeting, Reston, USA, 2015. Available online: https:/ tinyurl.com/ybm9huug (accessed on 9 January 2018).

25. Carrère, L.; Lyard, F.; Cancet, M.; Guillot, A.; Picot, N.; Dupuy, S. FES2014: A New Global Tidal Model. In Proceedings of the Ocean Surface Topography Science Team Meeting, Reston, USA, 2015. Available online: https: / / tinyurl.com/y9j9p4mf (accessed on 9 January 2018).

26. Valladeau, G.; Thibaut, P.; Picard, B.; Poisson, J.C.; Tran, N.; Picot, N.; Guillot, A. Using SARAL/AltiKa to improve Ka-band Altimeter measurements for Coastal Zones, Hydrology and ice: The PEACHI Prototype. Mar. Geod. 2015, 38, 124-142, doi:10.1080/01490419.2015.1020176.

27. Steunou, N.; Desjonquères, J.D.; Picot, N.; Sengenes, P.; Noubel, J.; Poisson, J.C. AltiKa Altimeter: Instrument description and in flight performance. Mar. Geod. 2015, 38, 22-42, doi:10.1080/01490419.2014.988835.

28. Tournadre, J.; Poisson, J.C.; Steunou, N.; Picard, B. Validation of AltiKa matching pursuit rain flag. Mar. Geod. 2015, 38, 107-123, doi:10.1080/01490419.2014.1001048.

29. Meyssignac, B.; Cazenave, A. Sea level: A review of present-day and recent-past changes and variability. J. Geodyn. 2012, 58, 96-109, doi:10.1016/j.jog.2012.03.005.

30. Picard, B.; Frery, M.L.; Obligis, E.; Eymard, L.; Steunou, N.; Picot, N. SARAL/AltiKa wet tropospheric correction: In-flight Calibration, retrieval strategies and performances. Mar. Geod. 2015, 38, 277-296, doi:10.1080/01490419.2015.1040903.

31. Zaron, E.D.; de Carvalho, R. Identification and reduction of retracker-related noise in altimeter-derived sea surface height measurements. J. Atmos. Ocean. Technol. 2016, 33, 201-210, doi:10.1175/JTECH-D-15-0164.1.

32. Dibarboure, G.; Boy, F.; Desjonqueres, J.D.; Labroue, S.; Lasne, Y.; Picot, N.; Poisson, J.C.; Thibaut, P. Investigating short-wavelength correlated errors on low-resolution mode altimetry. J. Atmos. Ocean. Technol. 2014, 31, 1337-1362, doi:10.1175/JTECH-D-13-00081.1.

33. Rémy, F.; Flament, T.; Michel, A.; Blumstein, D. Envisat and SARAL/AltiKa observations of the Antarctic Ice Sheet: A comparison between the Ku-band and Ka-band. Mar. Geod. 2015, 38, 510-521, doi:10.1080/01490419.2014.985347.

34. Legrésy, B.; Rémy, F. Using the temporal variability of the radar altimetric observations to map surface properties of the Antarctic ice sheet. J. Glaciol. 1998, 44, 197-206.

35. Wriedt, T. Mie Theory: A Review. In The Mie Theory: Basics and Applications; Hergert, W., Wriedt, T., Eds.; Springer: Berlin/Heidelberg, Germany, 2012; pp. 53-71. 
36. Vincent, P.; Steunou, N.; Caubet, E.; Phalippou, L.; Rey, L.; Thouvenot, E.; Verron, J. AltiKa: A Ka-band Altimetry Payload and System for Operational Altimetry during the GMES period. Sensors 2006, 6, $208-234$.

37. Aublanc, J.; Thibaut, P.; Lacrouts, C.; Boy, F.; Guillot, A.; Picot, N.; Rémy, F.; Blumstein, D. Altimetry Mission Performances over the Polar Ice Sheets: Cryosat-2, AltiKa and Sentinel-3A. In Proceedings of the Ocean Surface Topography Science Team Meeting, Miami, Florida, 2017. Available online: https://tinyurl.com/y7e7bckx (accessed on 9 January 2018).

38. Quartly, G.; Guymer, T.; Srokosz, A. The effects of rain on Topex radar altimeter data. J. Atmos. Ocean. Technol. 1996, 13, 1209-1229.

39. Tournadre, J.; Morland, J.C. The effects of rain on TOPEX/Poseidon altimeter data. IEEE Trans. Geosci. Remote Sens. 1997, 35, 1117-1135, doi:10.1109/36.628780.

40. Tournadre, J.; Lambin-Artru, J.; Steunou, N. Cloud and rain effects on AltiKa/SARAL Ka-band radar altimeter-Part I: Modeling and mean annual data availability. IEEE Trans. Geosci. Remote Sens. 2009, 47, 1806-1817, doi:10.1109/TGRS.2008.2010130.

41. Tournadre, J.; Lambin-Artru, J.; Steunou, N. Cloud and rain effects on AltiKa/SARAL Ka-band radar altimeter-Part II: Definition of a rain/cloud flag. IEEE Trans. Geosci. Remote Sens. 2009, 47, 1818-1826, doi:10.1109/TGRS.2008.2010127.

42. Prandi, P.; Debout, V.; Ablain, M.; Labroue, S. SARAL/Altika Validation and Cross Calibration Activities: Annual Report 2016; Technical Report; CLS: Ramonville Saint-Agne, France, 2016.

43. Thibaut, P.; Piras, F.; Poisson, J.C.; Moreau, T.; Aublanc, J.; Amarouche, L.; Picot, N. Convergent Solutions for Retracking Conventional and Delay Doppler Altimeter Echoes. In Proceedings of the Ocean Surface Topography Science Team Meeting, Miami, Florida, 2017. Available online: https:/ tinyurl.com/ybppndx6 (accessed on 9 January 2018).

44. Tournadre, J. Validation of Jason and envisat altimeter dual frequency rain flags. Mar. Geod. 2004, 27, 153-169, doi:10.1080/01490410490465616.

45. Tran, N.; Obligis, E.; Ferreira, F. Comparison of two Jason-1 altimeter precipitation detection algorithms with rain estimates from the TRMM Microwave Imager. J. Atmos. Ocean. Technol. 2005, 22, 782-794.

46. Tran, N.; Tournadre, J.; Femenias, P. Validation of envisat rain detection and rain rate estimates by comparing with TRMM data. IEEE Geosci. Remote Sens. Lett. 2008, 5, 658-662, doi:10.1109/LGRS.2008.2002043.

47. Adler, R.F.; Huffman, G.J.; Chang, A.; Ferraro, R.; Xie, P.P.; Janowiak, J.; Rudolf, B.; Schneider, U.; Curtis, S.; Bolvin, D.; et al. The Version-2 Global Precipitation Climatology Project (GPCP) monthly precipitation analysis (1979-Present). J. Hydrometeorol. 2003, 4, 1147-1167, doi:10.1175/1525-7541(2003)004<1147:TVGPCP>2.0.CO;2.

48. Poisson, J.; Thibaut, P.; Hoang, D.; Boy, F.; A. Guillot, A.N.P. Wavelet analysis of AltiKa measurements. In Proceedings of the Ocean Surface Topography Science Team, Constance, Germany, 28-31 October 2014.

49. Zech, W.; Senesi, N.; Guggenberger, G.; Kaiser, K.; Lehmann, J.; Miano, T.; Miltner, A.; Schroth, G. Factors controlling humification and mineralization of soil organic matter in the tropics. Geoderma 1997, 79, 117-161.

50. Hiernaux, P.; Mougin, E.; Diarra, L.; Soumaguel, N.; Lavenu, F.; Tracol, Y.; Diawara, M.; Jarlan, L. Rangeland response to rainfall and grazing pressure over two decades: Herbaceous growth pattern, production and species composition in the Gourma, Mali. J. Hydrol. 2009, 375, 114-127.

51. Brümmer, C.; Falk, U.; Papen, H.; Szarzynski, J.; Wassmann, R.; Brüggemann, N. Diurnal, seasonal, and interannual variation in carbon dioxide and energy exchange in shrub savanna in Burkina Faso (West Africa). J. Geophys. Res. Biogeosci. 2008, 113, doi:10.1029/2007JG000583.

52. Taylor, C.M.; Harris, P.P.; Parker, D.J. Impact of soil moisture on the development of a Sahelian mesoscale convective system: A case-study from the AMMA Special Observing Period. Q. J. R. Meteorol. Soc. 2010, 136, 456-470, doi:10.1002/qj.465.

53. Fatras, C.; Frappart, F.; Mougin, E.; Grippa, M.; Hiernaux, P. Estimating surface soil moisture over Sahel using ENVISAT radar altimetry. Remote Sens. Environ. 2012, 123, 496-507, doi:10.1016/j.rse.2012.04.013.

54. Fatras, C.; Frappart, F.; Mougin, E.; Frison, P.L.; Faye, G.; Borderies, P.; Jarlan, L. Spaceborne altimetry and scatterometry backscattering signatures at $\mathrm{C}$ - and Ku-bands over West Africa. Remote Sens. Environ. 2015, 159, 117-133, doi:10.1016/j.rse.2014.12.005.

55. Baup, F.; Mougin, E.; de Rosnay, P.; Hiernaux, P.; Frappart, F.; Frison, P.L.; Zribi, M.; Viarre, J. Mapping surface soil moisture over the Gourma mesoscale site (Mali) by using ENVISAT ASAR data. Hydrol. Earth Syst. Sci. 2011, 15, 603-616, doi:10.5194/hess-15-603-2011. 
56. Gruhier, C.; de Rosnay, P.; Hasenauer, S.; Holmes, T.; de Jeu, R.; Kerr, Y.; Mougin, E.; Njoku, E.; Timouk, F.; Wagner, W.; et al. Soil moisture active and passive microwave products: Intercomparison and evaluation over a Sahelian site. Hydrol. Earth Syst. Sci. 2010, 14, 141-156, doi:10.5194/hess-15-603-2011.

57. Frappart, F.; Fatras, C.; Mougin, E.; Marieu, V.; Diepkilé, A.; Blarel, F.; Borderies, P. Radar altimetry backscattering signatures at $\mathrm{Ka}, \mathrm{Ku}, \mathrm{C}$, and $\mathrm{S}$ bands over West Africa. Phys. Chem. Earth Parts A/B/C 2015, 83, 96-110, doi:10.1016/j.pce.2015.05.001.

58. Kerr, Y.H.; Waldteufel, P.; Richaume, P.; Wigneron, J.P.; Ferrazzoli, P.; Mahmoodi, A.; Al Bitar, A.; Cabot, F.; Gruhier, C.; Juglea, S.E.; et al. The SMOS soil moisture retrieval algorithm. IEEE Trans. Geosci. Remote Sens. 2012, 50, 1384-1403, doi:10.1109/TGRS.2012.2184548.

(C) 2018 by the authors. Licensee MDPI, Basel, Switzerland. This article is an open access article distributed under the terms and conditions of the Creative Commons Attribution (CC BY) license (http://creativecommons.org/licenses/by/4.0/). 